\title{
Assessment of investigation techniques for scyphozoan statoliths, with focus on early development of the jellyfish Sanderia malayensis
}

\author{
Anneke Heins ${ }^{1,2, *}$, Ilka Sötje ${ }^{3}$, Sabine Holst ${ }^{2}$ \\ ${ }^{1}$ University of Oldenburg, Institute for Biology and Environmental Sciences, 26129 Oldenburg, Germany \\ ${ }^{2}$ Senckenberg am Meer, German Center for Marine Biodiversity Research, 20146 Hamburg, Germany \\ ${ }^{3}$ University of Hamburg, Biocenter Grindel, Zoological Institute, 20146 Hamburg, Germany
}

\begin{abstract}
Statolith ageing techniques provide a useful tool in the study of age, growth, and population structure of several marine organisms. Previous investigations on scyphozoan statoliths demonstrated increased statolith numbers and size with increasing medusa size, as well as taxon-specific variations in statolith shape. Thus, statoliths are potentially useful for age determination and taxonomic studies on medusae. Unfortunately, studies on statoliths are difficult because of the fragile structure of the numerous tiny crystals and their hygroscopic nature. We evaluated the potential of various modified study techniques for scyphozoan statocysts and statoliths applied to early medusa stages of Sanderia malayensis Goette, 1886. Light microscopy was suitable to follow the increase of statolith numbers and sizes with age and allowed differentiation of various statolith shape types, which were confirmed by scanning electron microscopy. The use of the fluorescent marker calcein provided direct evidence for measurable statolith growth. Our results indicated that statoliths stopped growing after reaching a certain size while additional statoliths developed in the basal region of the statocyst. Micro-computed tomography data allowed visualization and morphometric measurements of statoliths, revealing interspecific differences that may be useful for phylogenetic studies. Statolith numbers were positively correlated with medusa age and bell diameter. Thus, statolith analyses could provide information on medusa age or size, both of which are important parameters for population structure analyses that are difficult to assess with currently applied techniques. Our study provides methodological bases for future studies to reveal further potential of scyphozoan statolith investigations for phylogenetic and ecological studies.
\end{abstract}

KEY WORDS: Cnidaria - Statocyst - Medusa - Slide scanner · Micro-tomography · Calcein · Scanning electron microscopy $\cdot \mathrm{SEM} \cdot$ Energy-dispersive X-ray spectroscopy $\cdot$ EDX

\section{INTRODUCTION}

Scyphozoan and cubozoan statocysts contain statoliths (crystals) composed of calcium sulfate hemihydrate (bassanite) (Becker et al. 2005, Sötje et al. 2011). Adult cubozoan medusae bear a single statolith in each of 4 statocysts (Sötje et al. 2011), whereas the statocysts of investigated adult scyphomedusae contain numerous single statoliths (Holst et al. 2007,

*Corresponding author: anneke.heins@uni-oldenburg.de

§Advance View was available online October 6, 2017
Sötje et al. 2018). Because the statoliths are the only solid, inorganic structures in the medusa bell, they provide the potential for age determination comparable to the calcified body parts of other marine organisms, for example squid and gastropod statoliths (e.g. Rodhouse \& Hatfield 1990, Barroso et al. 2005) and fish otoliths (e.g. Panfili et al. 2009). Age determination is an important tool for studies of population dynamics and could improve backtracking models of

(C) The authors 2018. Open Access under Creative Commons by Attribution Licence. Use, distribution and reproduction are unrestricted. Authors and original publication must be credited. 
jellyfish pathways and thus discovery of polyp habitats (Dulière et al. 2014, Gambill 2016), which play a key role in determining the timing and intensity of jellyfish blooms (Schiariti et al. 2015).

Scyphozoan statoliths have been described as trigonal-trapezohedral crystals composed of 6 trapezoids (side faces) and 3 pentagons on each side of the rod (head faces) (Sötje et al. 2017). The size, growth, and number of scyphozoan statoliths increase with increasing medusa size (e.g. Holst et al. 2007, Sötje et al. 2011 , 2017), indicating the potential of these crystals for medusa age determination, as previously shown for cubozoans (Gordon et al. 2004). Moreover, previous investigations on scyphozoan statocysts have revealed taxa-specific differences in the morphology of the statolith arrangement and in statolith shapes. Thus, statolith analyses may be useful for taxonomic and phylogenetic studies (Becker et al. 2005, Holst et al. 2007, 2016, Sötje et al. 2011, 2017). Difficulties in scyphozoan statolith analyses lie in the extremely hygroscopic nature of bassanite, which quickly transforms to dehydrate (gypsum) in contact with moisture (Becker et al. 2005, Boßelmann et al. 2007). Because of this and the fragility of the numerous tiny crystals, the few studies conducted on statolith development relating to medusa age are often based on few test animals or a unilateral spectrum of methods (Sötje et al. 2011, 2017, Hopf \& Kingsford 2013).

In the present study, we conducted the first comprehensive study on statoliths of a scyphomedusa belonging to the taxon Pelagiidae. We provide an extensive dataset of statocysts and statolith analyses on ephyrae and medusae of different ages. The development of ephyra to early medusa stages of Sanderia malayensis Goette, 1886 was documented with focus on the morphology and development of statocysts, on the analysis of statocyst number per specimen, statolith number per statocyst, statolith and statocyst shape and growth, and statolith chemistry. We used a combination of previously established and new methods, especially modified for the particular requirements of statoliths composed of basanite, in order to evaluate the utility of different techniques in future studies. Our methods included (1) light microscopic (LM) studies with a slide scanner, (2) application of the fluorescent marker calcein on statoliths combined with confocal laser scanning microscopy (cLSM), (3) 3-dimensional reconstructions of statocysts from X-ray micro-tomographic data, (4) scanning electron microscopy (SEM) of statoliths from different developmental stages, and (5) determination of the statolith chemical composition by energy-dispersive X-ray spectroscopy (EDX).

\section{MATERIALS AND METHODS}

\section{Cultivation of Sanderia malayensis}

Ephyrae were obtained from strobilating S. malayensis polyps (Fig. 1A-F) (for origin of polyp culture, see Adler \& Jarms 2009) cultured in darkness, at a constant temperature of $20^{\circ} \mathrm{C}$ in natural seawater (5-13 $\mu \mathrm{m}$ filtered, salinity $35, \mathrm{pH} 8.1 \pm 0.1$ ). The polyps were fed with 0 to $1 \mathrm{~d}$ old Artemia salina nauplii weekly. Detached ephyrae were removed from the culture daily and photographed individually in the extended state (Fig. 1G). Ephyrae released in the first 2 mo were used to define the normal morphology and identifiy specimens with malformations. Normal ephyrae released from the third month on were selected for the experiments. Some of these specimens were preserved directly after detachment $(0 \mathrm{~d}$ old, $\mathrm{n}=$ 11), whereas others were reared for $7,14,21,28,35$, or $42 \mathrm{~d}(\mathrm{n}=9,5,8,9,7$, or 10, respectively). The ephyrae were cultured separately in slightly aerated Erlenmeyer flasks $(100 \mathrm{ml}$ for 0 to $28 \mathrm{~d}$ old specimens, $200 \mathrm{ml}$ for $>28$ to $45 \mathrm{~d}$ old specimens) in seawater at $20^{\circ} \mathrm{C}$. The cultured animals were fed with Artemia salina nauplii and mashed Aurelia aurita medusae every third day starting on the day of their release (for details, see Table S1 in the Supplement at www.intres.com/articles/suppl/m591p037_supp.pdf).

\section{Growth of cultured specimens}

Ephyrae with 15 or 16 rhopalia without malformations (reared to $0,7,14,21,28,35$, and $42 \mathrm{~d} ; \mathrm{n}=6,3$, $3,6,6,4$, and 6 , respectively) were selected for statocyst and statolith analyses. Stereomicroscopic photographs were taken on the day of their release $(0 \mathrm{~d}$ old) and on the day of their fixation in $100 \%$ ethanol to document their growth. Four diameters and 3 marginal lappet parameters were measured (for details see Fig. 1G and caption of Table S2 in the Supplement). The percentage increase of each parameter was calculated using the following equation:

$$
\begin{aligned}
& \text { increase } \%=100^{*} \text { (second measurement - } \\
& \text { first measurement)/first measurement }
\end{aligned}
$$

Carbon weight $(\mathrm{CW} ; \mathrm{mg})$ and the instantaneous growth rate $\left(\mu_{i} \mathrm{~d}^{-1}\right)$ were calculated using the equations based on Lilley et al. (2014a):

$$
\mathrm{CW}=0.24 \times D_{\mathrm{t}}^{3}
$$

and

$$
\mu=\ln \left(\mathrm{CW}_{2} / \mathrm{CW}_{1}\right) /\left(t_{2}-t_{1}\right)
$$




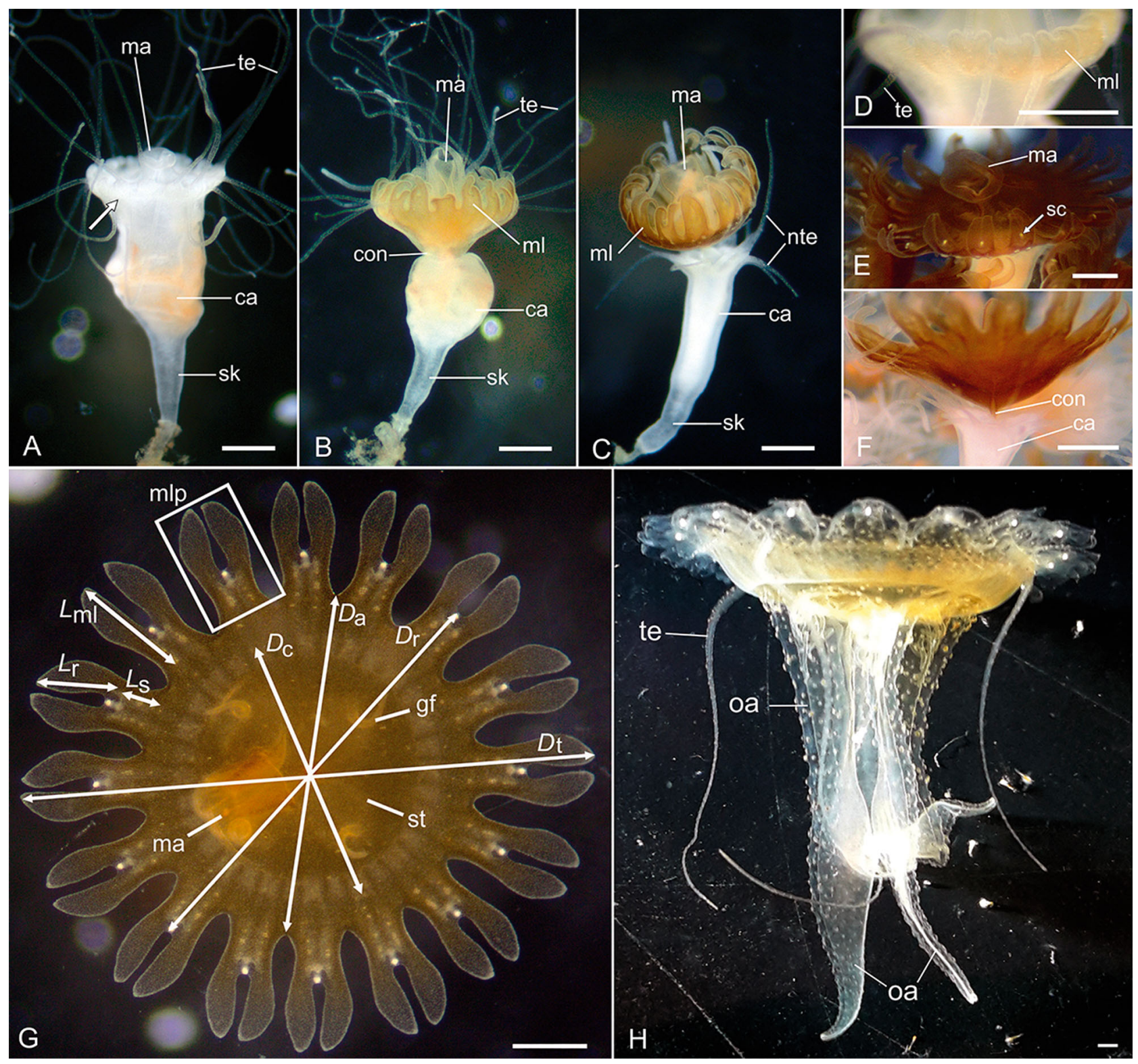

Fig. 1. Strobilation and development of Sanderia malayensis. (A-C) Process of monodisc strobilation. (A) Circular constriction (arrow) of the polyp calyx below the tentacle region. (B) Developing ephyra with thinning connection to the polyp and beginning reduction of tentacles. (C) Advanced ephyra and polyp with regenerating tentacles. (D-F) Close up of the developing ephyra showing (D) the development of marginal lappet pairs between the former polyp tentacles, (E) the appearance of statocysts between the lappet pairs, and (F) the thin connection of ephyra and polyp in advanced strobilation. (G) Ephyra after release from the polyp $(0 \mathrm{~d}$ old $)$ in aboral view showing the parameters measured (for details see Table S2 in the Supplement at www.int-res.com/articles/suppl/m591p037_supp.pdf). (H) Side view of a $42 \mathrm{~d}$ old medusa with long oral arms and tentacles. $D_{\mathrm{a}}$ : adradial diameter; ca: calyx $D_{\mathrm{c}}$ : central disc diameter; con: connection; gf: gastral filament; $L_{\mathrm{s}}$ : lappet stem length; ma: manubrium; ml: marginal lappet $\left(L_{\mathrm{ml}}=\right.$ length); mlp: marginal lappet pair; nte: new developed tentacles; oa: oral arm; $D_{\mathrm{r}}$ : rhopalar diameter; $L_{\mathrm{r}}$ : rhopalar lobe length; sc: statocyst; sk: stalk; st: stomach; $D_{\mathrm{t}}$ : total body diameter; te: tentacles. Scale bars $=500 \mu \mathrm{m}$

where $D_{\mathrm{t}}$ is the total ephyra diameter measured between opposite lappet tips on the day of release $\left(t_{1}\right)$ and on the day of preservation of the same specimen $\left(t_{2}\right)$, respectively. Resulting carbon weights $\left(\mathrm{CW}_{1}\right.$, $\mathrm{CW}_{2}$ ) were used for the calculation of growth rates $\mu$ (in \%) between $t_{1}$ and $t_{2}$.

\section{Light microscopic statolith analyses}

One specimen per age with 16 developed statocysts was chosen for the LM statolith analyses of each of its statocysts. Differences in the mean statolith numbers were compared between all statocysts and 
4 randomly selected statocysts from the same specimen. Because no significant differences were found (see 'Results'), 4 statocysts were randomly chosen for further statolith analyses of additional specimens at each age. The marginal lappet pairs were dissected under a stereomicroscope (Leica M125) in pure ethanol. The subsequent removal of tissues surrounding the statocyst was conducted in water-free glycerol. A high-precision microscope cover glass $\left(22 \times 22 \mathrm{~mm}^{2}\right.$, thickness $170 \pm 5 \mu \mathrm{m}$ ) was carefully applied, and images of the statocysts were taken using a microscope (Leica DM2500) equipped with a camera (Leica DFC295) for later size measurements.

Subsequently, the cover glass was moved in a slow, circular motion until the tension between the 2 glass planes opened the statocyst and statoliths were distributed in 1 layer on the slide. The sample was sealed with transparent nail polish before further analyses were conducted 12-48 h after preparation. The samples were scanned with a slide scanner (Leica DM6000 B) equipped with a camera (Leica DFC 425) at 200-fold magnification with 8-bit monochrome acquisition channel and an image auto focus. The system was adjusted to the specific characteristics of the translucent statolith crystals by a Leica Microsystems technician to achieve an optimized image auto focus and to avoid measurement errors due to image overlaps in the stitched images. The resulting tiff-images were stitched together (Leica MM AF, edition 1.5.0), and the stitched image was searched for insufficiently focused statoliths, which were photographed again.

Each statolith that appeared on the images was measured and its orientation to the slide was documented. Three statolith orientations to the microscopic slide were defined: (1) side-face orientation (axes approximately parallel to the slide), (2) headface orientation (approximately orthogonal to the slide), and (3) tilted orientation (inclined position between cover glass and slide). Due to this preparation method, the statoliths were kept in good condition, and broken statoliths appeared only in exceptional cases. Tilted or broken statoliths were counted but not measured. The length and width of each side-face-oriented statolith were measured and the length:width (aspect) ratio was calculated. Three statolith shapes were defined according to the terms used by Sötje et al. (2017): (1) disc-shaped with aspect ratio <1 (Fig. 2A), (2) rod-shaped with aspect ratio $\geq 1$ and $\leq 5$ (Fig. 2B), (3) needle-shaped with aspect ratio $>5$ (Fig. $2 \mathrm{C}$ ). The length $\times$ width was used to calculate the approximate statolith crosssectional area for each statolith.
In head-face-oriented statoliths, the side lengths and the diameters of the statolith cross profiles were measured (Fig. 2D-G). These parameters were considered equal if they differed by less than $15 \%$. Four symmetries of the hexagonal statolith cross profile were defined: (1) 'equilateral' hexagon with equal side lengths and diameters (Fig. 2D), (2) 'isogonal' hexagon with 3 short alternating with 3 long sides and 3 equal diameters (Fig. 2E), (3) 'parallelogonal' hexagon with 2 opposite pairs of equally long sides and 2 equal diameters, combined with 1 opposite pair of longer or shorter side length and diameter (Fig. 2F), (4) 'irregular' hexagon with unequally long opposite sides, at least 3 different side lengths, and 2 equal diameters (Fig. 2G).

\section{Calcein experiments}

Statoliths labelled with calcein (Sigma-Aldrich, product number C0875) were used to estimate growth following the methods of Sötje et al. (2017). Four calcein treatments were performed with 4 normal ephyrae using 2 calcein concentrations: (1) 2 incubations with $100 \mu \mathrm{mol} \mathrm{l}^{-1}$ calcein, (2) 2 incubations with

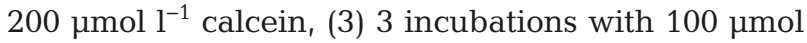
$\mathrm{l}^{-1}$ calcein, and (4) 3 incubations with $200 \mu \mathrm{mol} \mathrm{l}^{-1}$ calcein. The specimens were cultured in Erlenmeyer flasks in calcein-seawater solutions for $3 \mathrm{~d}$ of each incubation. The first incubation was conducted with 1 to $4 \mathrm{~d}$ old specimens, and the second incubation was started $28 \mathrm{~d}$ after the end of the first incubation. The third incubation, conducted with 2 specimens (Treatments 3 and 4), was started $14 \mathrm{~d}$ after the end of the second incubation. After the last incubations, the test animals were photographed in the relaxed state. Statocyts were scanned using cLSM. Statoliths in headface orientation showing 2 fluorescent hexagonal lines inside the statolith (Fig. 2J,K) were analyzed (Treatment 3: $\mathrm{n}=5$, Treatment $4: \mathrm{n}=13$ ). The statolith diameters and increments were measured on 2 virtual cut-planes generated with the software AVIZO (9.0) (for details, see Sötje et al. 2017).

\section{Scanning electron microscopy and energy- dispersive X-ray spectroscopy}

Statoliths of one $0 \mathrm{~d}$ old and one $42 \mathrm{~d}$ old specimen were investigated with SEM after Sötje et al. (2017). Two large statoliths from the $0 \mathrm{~d}$ old ephyra and 5 statoliths from the $42 \mathrm{~d}$ old medusa were analyzed by EDX (Becker et al. 2005). 


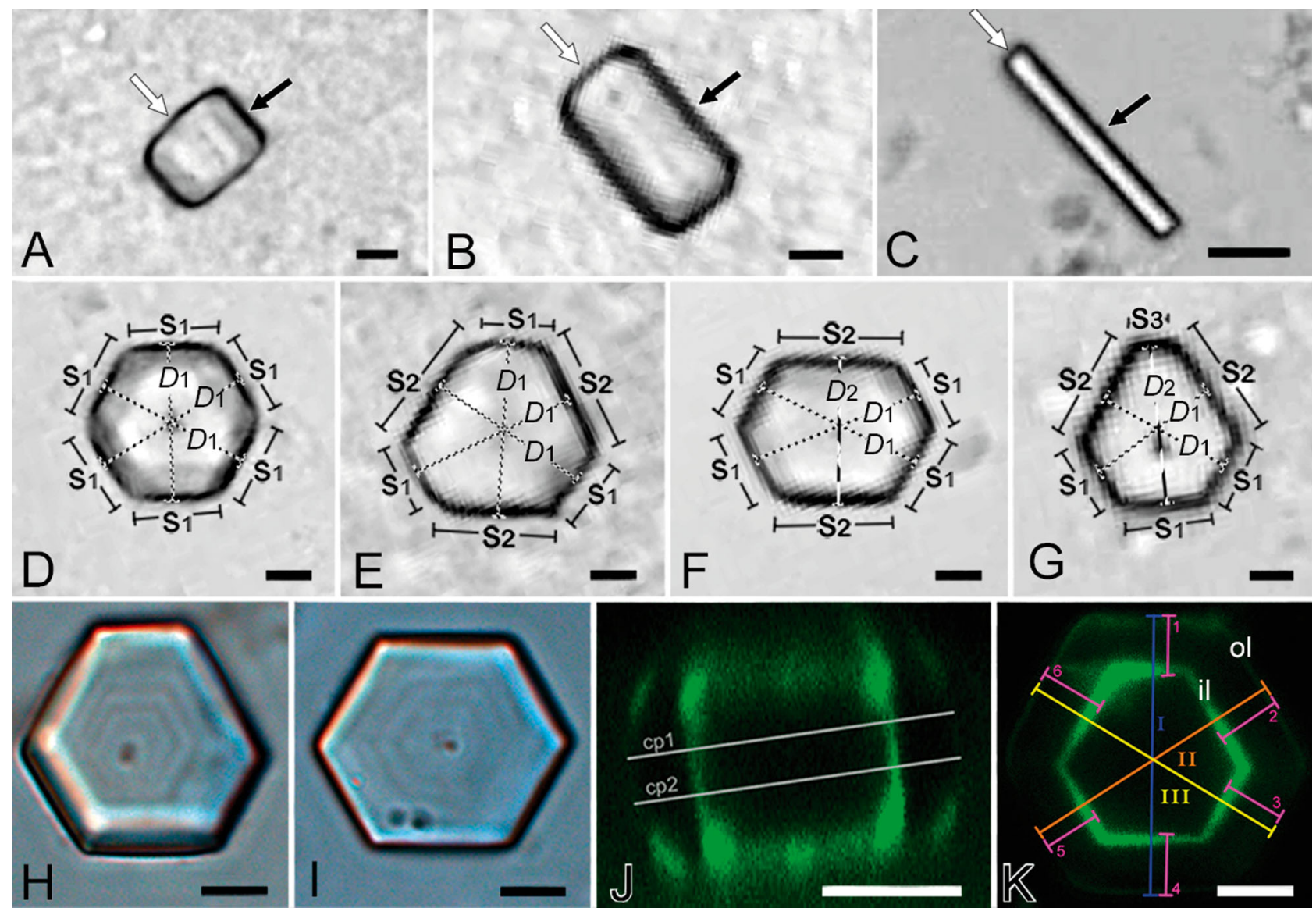

Fig. 2. Statoliths of Sanderia malayensis in various shapes and orientations. (A-C) Statoliths with axes oriented approximately parallel to the microscope slide (side-face orientation) showing the dimensions of head faces (white arrows) and side faces (black arrows): (A) disc shape, (B) rod shape, (C) needle shape. (D-G) Statoliths with axes oriented approximately orthogonal to the microscope slide (head-face orientation), showing the dimensions of statolith cross profiles: (D) equilateral, (E) isogonal, (F) parallelogonal, $(\mathrm{G})$ irregular. $(\mathrm{H}, \mathrm{I}) \mathrm{1}-2 \mu \mathrm{m}$ wide ring structures inside head-face-oriented crystals at 1000-fold magnification. $(\mathrm{J}, \mathrm{K})$ Statolith after treatment with the fluorescent marker calcein under excitation by confocal laser scanning microscopy: (J) side view; parallel white lines indicate the cut-planes generated for measurements of statolith increments, (K) view of cut-plane showing the measurements of statolith diameters (I-III) and increments (1-6). cp: cut-plane; $D$ : diameter; il: inner fluorescent line; ol: outer fluorescent line; $\mathrm{S}$ : side. Scale bars $=5 \mu \mathrm{m}$

\section{Micro-computed tomography}

One statocyst from each of $3 \mathrm{~S}$. malayensis specimens $(0,14$, and $42 \mathrm{~d}$ old $)$ fixed in pure ethanol was used for micro-computed tomographic analyses (Xradia MicroXCT-200 Xray imaging system, Carl Zeiss Microscopy). The statocysts were embedded in LR-White, scanned at the highest possible resolution (40x objective), and analyzed with the software AVIZO (9.0) after Holst et al. (2016). The statoliths were automatically counted and measured by the label analysis module of the software providing 3 length measurements in $x^{-}, y^{-}$, and $z$-axes for each statolith ('Bounding Box' values), maximum length measurements ('Length3D' values), as well as volume measurements ('Volume3D' values, see Holst et al. 2016). The highest and the lowest Bounding Box values for each statolith were used for the evaluation of the approximate statolith cross-sectional areas.

\section{Statistics}

The test statistics were conducted with the software SigmaPlot (12.5). Correlations with the specimen sizes and ages were tested by the Pearson product moment correlation or a Spearman rank order correlation. The Kruskal-Wallis 1-way analysis of variance (ANOVA) on ranks was used for comparisons between age groups. Comparisons between 2 groups were conducted with a $t$-test or a Mann-Whitney rank sum test. 


\section{RESULTS}

\section{Ephyra development}

All observed strobilations were monodisc (Fig. 1A-F) and took 2 to $4 \mathrm{~d}$. The polyp tentacles were reduced, and the rhopalia with statocysts appeared in the clefts between 2 rhopalar lobes (Fig. 1E). The $0 \mathrm{~d}$ old ephyrae had $D_{\mathrm{t}}=3.8 \pm 0.2 \mathrm{~mm}$ and $D_{\mathrm{r}}=2.83 \pm 0.2 \mathrm{~mm}$ (mean $\pm \mathrm{SD}, \mathrm{n}=6$; Table $\mathrm{S} 2$ in the Supplement). Morphological malformations were documented in $33 \%$ ( $\mathrm{n}=184)$ of newly-detached ephyrae $(\mathrm{n}=560)$, mostly at the marginal lappets (Fig. 3A,B).

The rhopalia numbers varied between 9 and 21 (Fig. 3C). Specimens with $15(25.0 \%, \mathrm{n}=140)$ and 16 $(23.8 \%, \mathrm{n}=133)$ rhopalia represented $48.8 \%$ of all
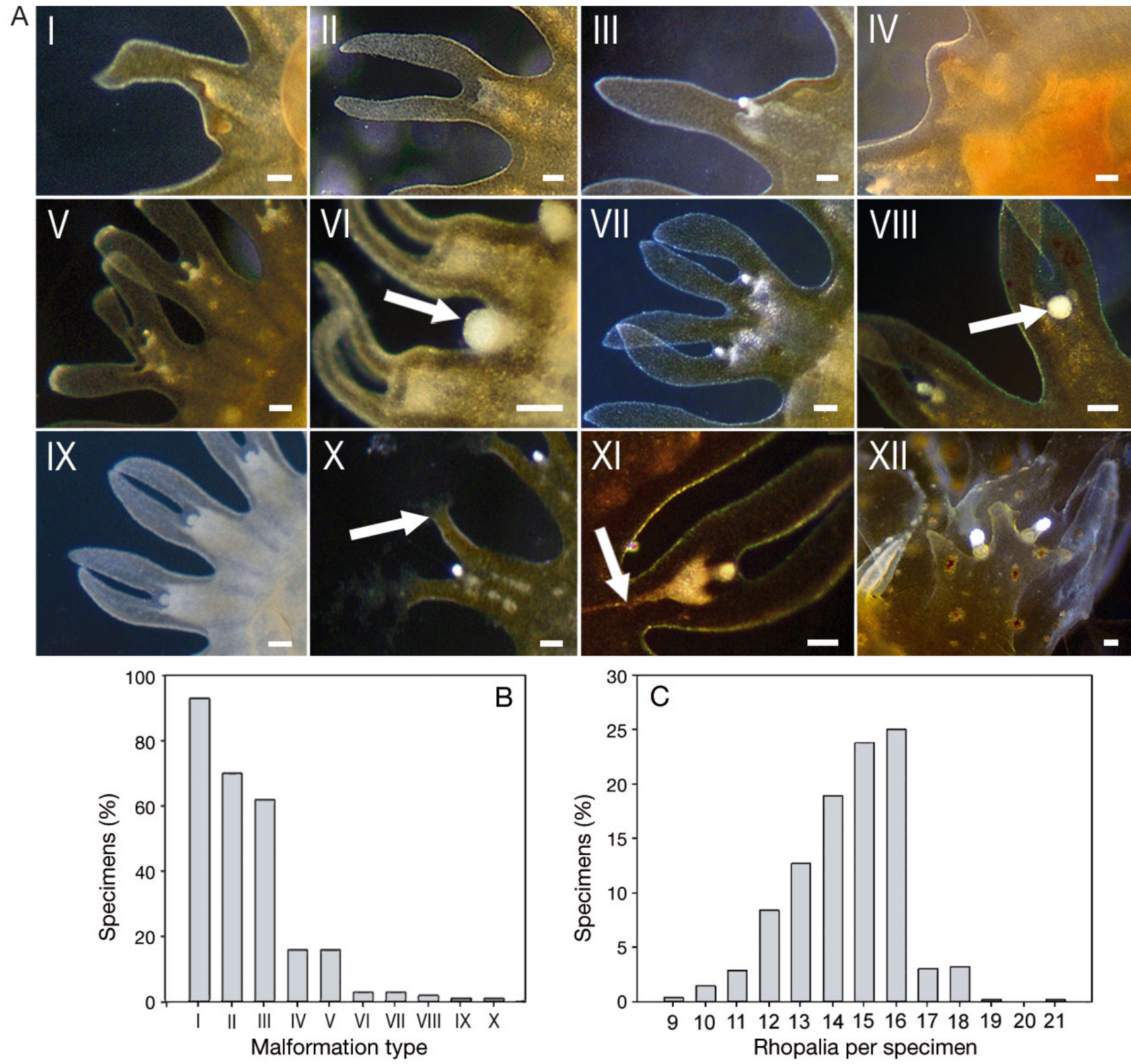

Fig. 3. Types of malformations and recorded rhopalia numbers in Sanderia malayensis. (A) Observed malformation types. I: absence of 1 rhopalar lobe and rhopalium; II: absence of rhopalium in the cleft of normally developed lobe pair; III: rhopalium with 1 missing rhopalar lobe; IV: absence of marginal lappet pair and rhopalium; V: more than 2 rhopalar lobes at 1 marginal lappet stem; VI: incompletely reduced polyp tentacles (arrow); VII: 2 marginal lappet pairs on the same lappet stem; VIII: exceptionally large statocyst (arrow); IX: white-opaque coloration; X: degenerated body parts (arrow shows degenerated rhopalar lobe); XI: slim marginal lappets with narrow rhopalar canal (arrow); XII: 2 rhopalia in the cleft between 1 marginal lappet pair. Scale bars $=100 \mu \mathrm{m}$. (B) Percentages of malformation types in newly released ephyrae $(\mathrm{n}=184)$. (C) Percentages of rhopalia numbers in newly released ephyrae $(\mathrm{n}=560)$ 
observed ephyrae, and both were considered to be normally developed. Four of the 0 d old ephyrae chosen for statolith analysis (15 rhopalia: $\mathrm{n}=9,16$ rhopalia: $\mathrm{n}=29$ ) later developed malformations. Two ephyrae cultured for $7 \mathrm{~d}$ developed exceptionally slim marginal lappets with abnormally narrow rhopalar canals (Fig. 3A, type XI); 2 specimens, cultured for $35 \mathrm{~d}$, developed additional rhopalia in at least 1 of their marginal lappet pairs (Fig. 3A, type XII). These specimens were analyzed separately.

The time of the appearance of 6 morphological features (Table 1) documented during development from ephyrae to $42 \mathrm{~d}$ old medusae (Fig. 1H) was rather variable. All measures (Fig. 1G) on specimens without malformations increased significantly with the age of the specimens (Pearson correlations for $D_{\mathrm{t}}$, $D_{\mathrm{r}}, D_{\mathrm{a}}, D_{\mathrm{c}}, L_{\mathrm{ml}}, L_{\mathrm{r}}$ [see legend of Fig. $1 \mathrm{G}$ for definitions]: $\mathrm{p} \leq$ 0.001; Spearman correlation for $L_{\mathrm{s}}: \mathrm{p} \leq$ 0.001 ; Fig. 4A). Specimens reared to $42 \mathrm{~d}$ had a mean $D_{\mathrm{r}}$ of $10.5 \pm 1.1 \mathrm{~mm}(\mathrm{n}=6)$ corresponding to $327 \pm$ $76 \%$ of the mean $D_{\mathrm{r}}$ of the same specimens at $0 \mathrm{~d}$ $(2.5 \pm 0.3 \mathrm{~mm}$; Table S2, Fig. 4B). Although the diameters of $42 \mathrm{~d}$ old specimens were smaller than those of $35 \mathrm{~d}$ old specimens (Fig. 4A), the percentage growth was highest in $42 \mathrm{~d}$ old specimens (Fig. 4B), probably due to the smaller initial diameters of the latter at $0 \mathrm{~d}$ (Table S2). The highest growth of body parts in the $42 \mathrm{~d}$ old specimens was measured in the central disc $(363 \pm 58 \%)$ and the adradial diameters $(361 \pm 72 \%)$, whereas the lowest growth was documented for the marginal lappets $(158 \pm 52 \%)$. These results reflect the transformation from the starshaped ephyra bell with deep marginal clefts to the more circular medusa bell. The instantaneous growth rate $(\mu)$ was $17.0 \pm 3.5 \% \mathrm{~d}^{-1}$ for $7 \mathrm{~d}$ old specimens and decreased with the age of specimens to $9.3 \pm 0.9 \%$ $\mathrm{d}^{-1}$ in $42 \mathrm{~d}$ old specimens (Table $\mathrm{S} 2$ ).

\section{Statolith numbers}

The mean value of statolith numbers from all 16 statocysts from 1 specimen did not significantly differ from the mean value of statolith numbers from 4 randomly chosen statocysts from that specimen at any age $\left(0-35 \mathrm{~d}\right.$ : $t$-test, $\mathrm{p} \geq 0.05, \mathrm{df} 18, \mathrm{n}_{\text {small }}=4, \mathrm{n}_{\text {big }}=$ 16; 42 d: Mann-Whitney rank sum test $\mathrm{p} \geq 0.05, T=$ $40, \mathrm{n}_{\text {small }}=4, \mathrm{n}_{\text {big }}=16$ ), indicating that statoliths from 4 statocysts were sufficient for analysis.

The LM analyses of 220 statocysts from 34 specimens without malformations revealed higher numbers of statoliths in older specimens. Fewer than 100 statoliths per statocyst were observed in 0 to $14 \mathrm{~d}$ old
Table 1. Percentages of Sanderia malayensis specimens (n) in which morphological features were present 0 to $42 \mathrm{~d}$ after their release. Time (d): days after release; NC: nematocyst clusters

\begin{tabular}{|c|c|c|c|c|c|c|c|}
\hline $\begin{array}{l}\text { Time } \\
\text { (d) }\end{array}$ & $\mathrm{n}$ & $-\mathrm{I}$ & $\begin{array}{l}\text { Oral } \\
\text { arms }\end{array}$ & $\begin{array}{l}\text {-Ten } \\
\text { Buds }\end{array}$ & $\begin{array}{l}\text { tacles- } \\
\text { Elon- } \\
\text { gated }\end{array}$ & $\begin{array}{c}\text { Brown } \\
\text { pigmented } \\
\text { NC }\end{array}$ & $\begin{array}{c}\text { Trans- } \\
\text { lucent } \\
\text { bell }\end{array}$ \\
\hline 0 & 11 & 72.7 & - & - & - & - & - \\
\hline 7 & 9 & 44.4 & - & - & - & - & - \\
\hline 14 & 5 & 100 & 60 & - & - & - & - \\
\hline 21 & 8 & 100 & 100 & 60 & - & - & - \\
\hline 28 & 9 & 100 & 100 & 100 & 44.4 & 22.2 & - \\
\hline 35 & 7 & 100 & 100 & 100 & 85.7 & 85.7 & 14.3 \\
\hline 42 & 10 & 100 & 100 & 100 & 100 & 100 & 60 \\
\hline
\end{tabular}

specimens, whereas as many as 250 statoliths were analyzed in 35 and $42 \mathrm{~d}$ old specimens. The statoliths per statocyst showed high variability within each age group, leading to overlaps between the groups (Fig. 4C). Nevertheless, differences in statolith numbers among the 7 age groups (Kruskal-Wallis ANOVA on ranks, $H=205.032, \mathrm{p} \leq 0.001, \mathrm{n}=220$ ) and the increase in the statoliths per statocyst with age of the specimens (Spearman correlation, $\mathrm{r}^{2}=$ $0.962, \mathrm{p} \leq 0.001, \mathrm{n}=220$; Fig. 4D) were significant. Thus, statoliths per statocyst increased significantly with age. Statoliths per statocyst also increased significantly with the size ( $D_{\mathrm{r}}$ and $D_{\mathrm{t}}$-diameters) of the specimens (Spearman correlation, $\mathrm{r}^{2}=0.932$ and 0.938, $\mathrm{p} \leq 0.001, \mathrm{n}=220$; Fig. 4E,F). The specimens which had developed malformations had significantly lower mean statoliths per statocyst than normal ones at the same age ( $t$-test specimens with additional rhopalia: $\mathrm{p}<0.001$, df $34, \mathrm{n}_{\text {normal }}=28, \mathrm{n}_{\text {malformed }}=8$; Mann-Whitney rank sum test specimens with slim marginal lappets: $\mathrm{p}<0.05, \mathrm{n}_{\text {normal }}=24, \mathrm{n}_{\text {malformed }}=8$ ).

The label analyses of tomographic data revealed 41,68 , and 194 statoliths in the statocysts of 0,14 , and $42 \mathrm{~d}$ old specimens, respectively. The statolith numbers determined by LM investigations were in similar magnitudes of 24-30 in $0 \mathrm{~d}, 50-74$ in $14 \mathrm{~d}$, and $217-241$ in $42 \mathrm{~d}$ old specimens (Table S3 in the Supplement).

\section{Statolith shapes}

The majority of statoliths $(70.6 \%, \mathrm{n}=17553)$ investigated with the LM method appeared in almost parallel orientation to the slice (side-face orientation, Fig. 5A). The percentage of the unmeasurable tilted statoliths was low at all ages (1.8-11.0\%). 

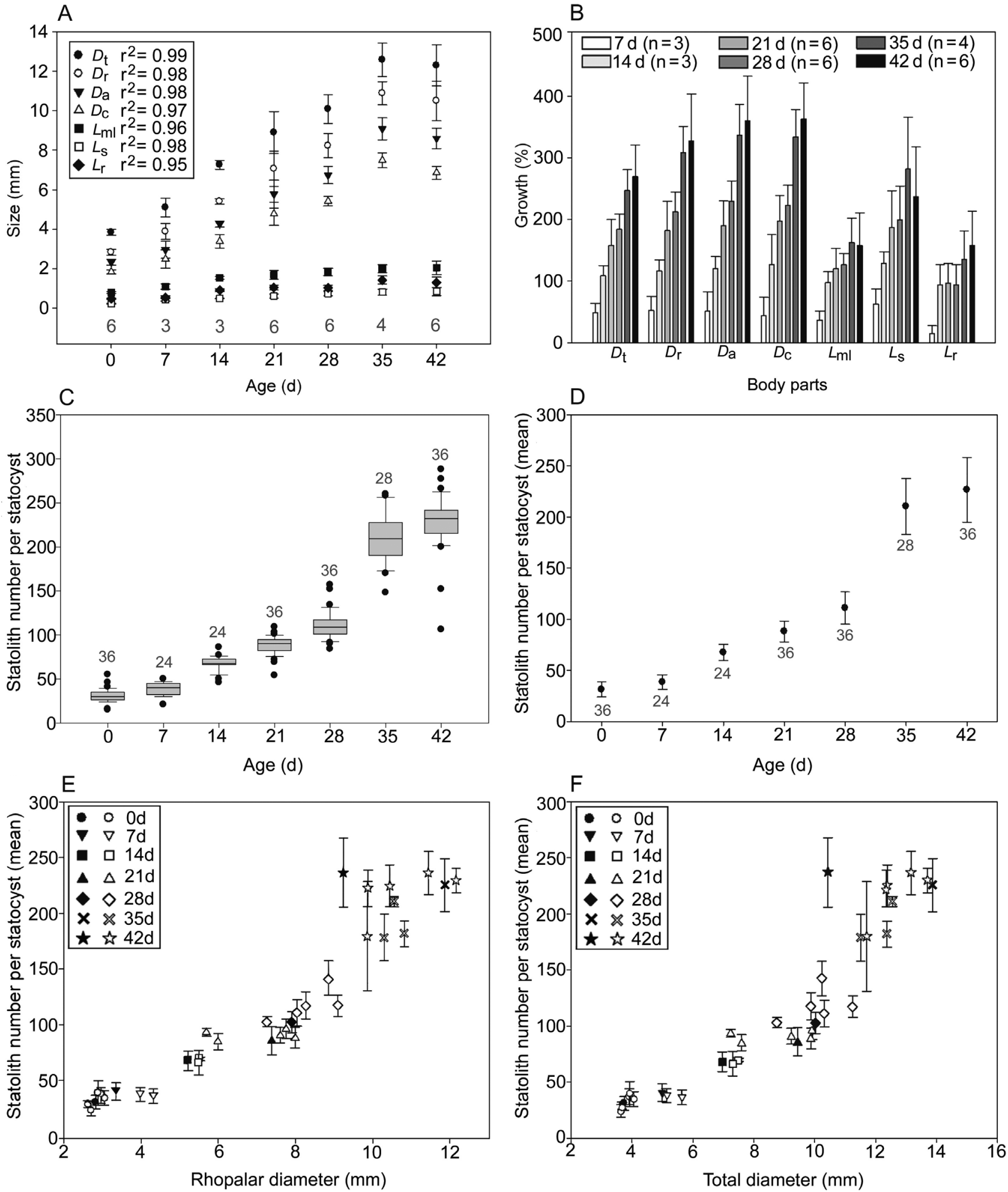

Fig. 4. Growth of body parts and increase of statoliths with age in Sanderia malayensis. (A) Absolute growth of different body parts (see legend of Fig. 1 for definitions). (B) Percentage growth of different body parts. (C) Statolith numbers. Lines: medians; vertical boxes: 25th and 75th percentiles; whiskers: 10th and 90th percentiles; dots: outliers. (D) Means ( \pm SD) of statolith numbers per statocyst. $(\mathrm{E}, \mathrm{F})$ Individual means $( \pm \mathrm{SD})$ of statoliths per statocyst in specimens of different sizes. Black symbols: $\mathrm{n}=16$ statocysts; white symbols: $\mathrm{n}=4$ statocysts. Grey numbers in $(\mathrm{A})$ : number of measured individuals; in $(\mathrm{C}, \mathrm{D})$ : number of 

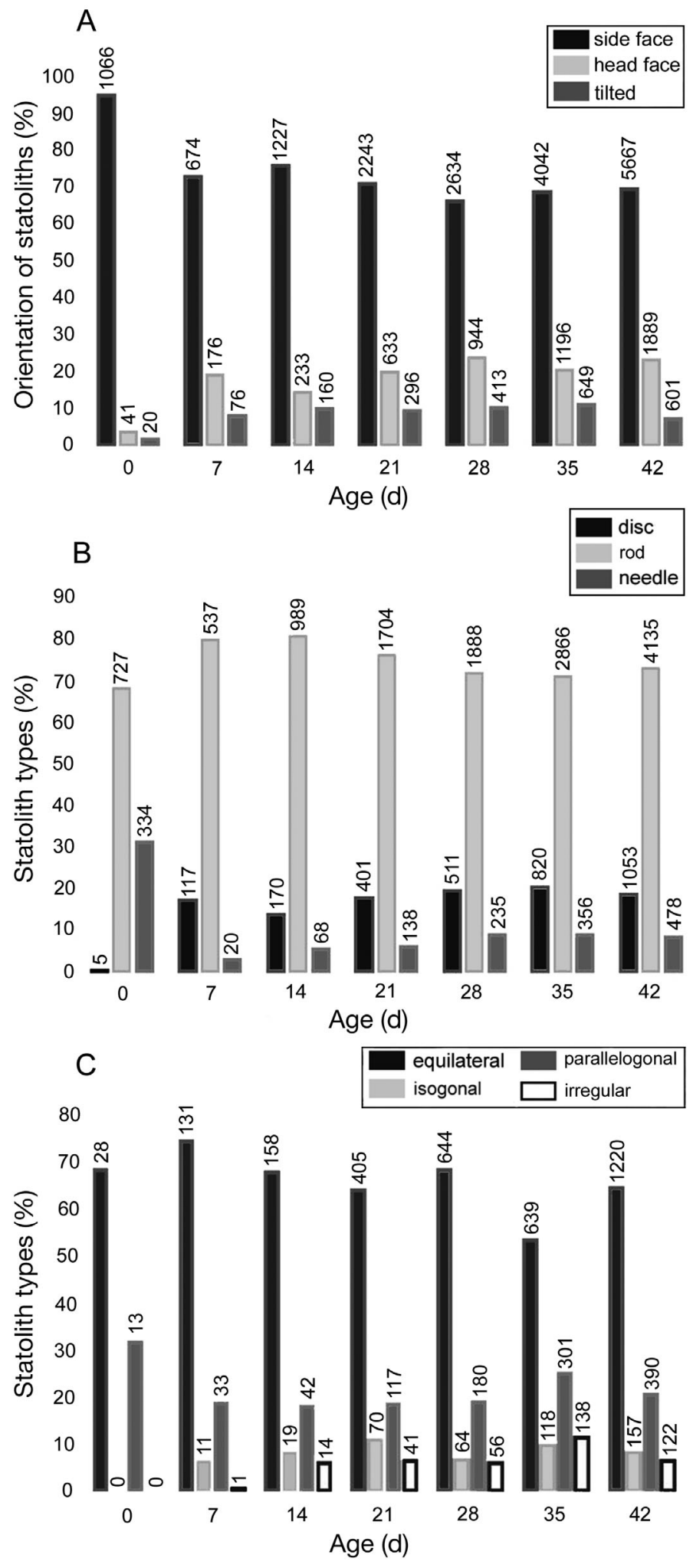

Fig. 5. Statolith orientations and shapes from Sanderia malayensis of different ages. (A) Orientation of statoliths to the microscopic slide. (B) Shape types of side-face-oriented statoliths. (C) Shape types of head-face-oriented statoliths. See Fig. 2 for illustrations of the different shapes. Numbers above bars: number of statoliths
In side-face-oriented statoliths ( $\mathrm{n}=17553$ ), rod-shaped was the most common type throughout all ages from 0 to $42 \mathrm{~d}$ (mean $74.3 \pm 4.6 \%$, range 68.2-80.6\%; Fig. 5B), representing the typical statolith shape of Sanderia malayensis. The disc-shaped statolith was the second most frequent type $(17.9 \pm 2.2 \%, 13.9-20.3 \%)$ in the statocysts of the 7 to $42 \mathrm{~d}$ old specimens, which contained few needle-shaped statoliths (6.8 \pm $2.4 \%, 3-8.9 \%$ ). In contrast, needle-shaped statoliths were more frequent $(31.3 \%)$ than the discshaped statoliths $(0.5 \%)$ in statocysts of $0 \mathrm{~d}$ old specimens. Each shape type represented an intact crystal with straight edges (Fig. 2A-C) and differed from broken fragments which appeared as splinter-like particles in very few preparations. Most statoliths in head-face orientation had an equilateral symmetry (65.8 $\pm 6.4 \%$, 53.4-74.4\%; Fig. 5C). At 1000× magnification, LM photographs of head-face-oriented statoliths showed fine hexagonal ring structures of 1-2 $\mu \mathrm{m}$ per ring inside the crystals, which appeared parallel to the hexagonal statolith cross profile (Fig. 2H,I).

In contrast to the LM images (up to 4.0 pixel $\mu \mathrm{m}^{-1}$ at $20 \times$ magnification, Fig. $\left.2 \mathrm{~A}-\mathrm{G}\right)$, the tomographic reconstructions (about 2.0 pixel $\mu \mathrm{m}^{-1}$ ) did not reflect the real statolith shapes, with planar surfaces and straight edges (Fig. 6A,B). The analysis of labeled statocysts (Fig. 6C) allowed visualization and automated morphometric measurements of single statoliths in 3 dimensions (Fig. 7A,B), but did not allow conclusions on the actual statolith shape types and dimensions, which were not accurately displayed in the tomographic reconstructions. Hence, it was not possible to distinguish between disc-shaped and rod-shaped statoliths because the orientation of head faces and side faces was not determinable as was possible in the LM photographs (Fig. 2A-C). However, the reconstructions revealed that small elongated statoliths were more abundant in the proximal than in the distal region of the statocyst (Fig. 6A-C).

Although the statoliths were often partly covered with tissue remnants, the high resolution of SEM micrographs (up to 191.7 pixels $\mu \mathrm{m}^{-1}$ ) provided good depictions of statolith shapes, demonstrating high variability of geometric forms (Fig. 6D-I). However, the pointed tips of the statolith head faces often were not accurately displayed in the SEM micrographs. In addition to 


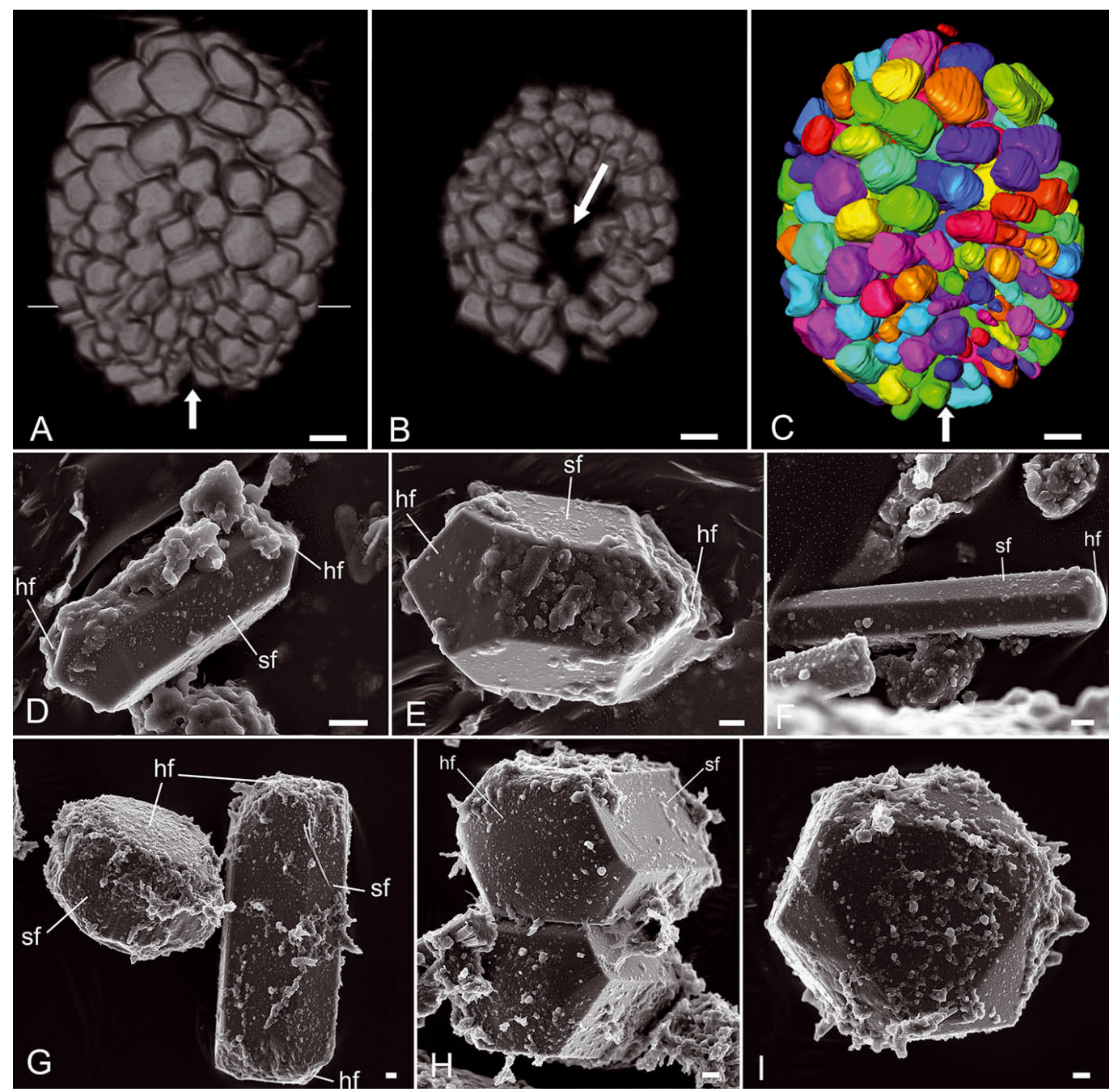

Fig. 6. Statocysts and statoliths of Sanderia malayensis. (A-C) Tomographic reconstructions of statocysts from a $42 \mathrm{~d}$ old medusa. White arrows indicate the basal region. (A) Statocyst in side view, white lines indicate the level of the generated virtual cut. (B) View of lower half of statocyst from the basal region after the virtual cut of the upper half (as shown in A) highlighting the cavity in the central basal area (arrow). (C) Statocyst in side view after the label analysis of separated statoliths. (D-I) Scanning electron micrographs of statoliths (hf: head face; sf: side face). (D,E) Statoliths of 0 d old ephyra showing variations in rod shape. (F-I) Shapes of statoliths from $42 \mathrm{~d}$ old medusa: (F) needle, (G) disc and long rod, (H) short rod, (I) equilateral. Scale bars $=(A-C) 10 \mu \mathrm{m},(D-I) 1 \mu \mathrm{m}$

the rod-, disc-, and needle-shaped statoliths documented by LM photographs (Fig. 5B), the SEM showed statoliths with almost equilateral sides in all dimensions (Fig. 6I).

\section{Statolith growth}

The statolith volumes revealed by the label analyses of tomographic data (Fig. 7C), as well as the calculated mean cross-sectional areas (length $\times$ width) of the statoliths in side-face orientation investigated by LM (Fig. 7D) confirmed a correlation of statolith size with age of the specimens (Spearman correlation micro-CT: $\mathrm{p}<0.001, \mathrm{r}^{2}=0.508, \mathrm{n}=303$; Spearman correlation LM: $\left.\mathrm{p}<0.001, \mathrm{r}^{2}=0.112, \mathrm{n}=17553\right)$. However, the mean values, medians, and maximum values of LM measurements showed clear growth until the second (14 d) to third (21 d) week only (Fig. 7D), suggesting that newly developed statoliths may have reached their final size during that period.

Both calcein concentrations (100 and $200 \mu \mathrm{mol} \mathrm{l}^{-1}$ ) caused clearly visible fluorescence hexagonal lines inside the statolith (Fig. 2K), which allowed repeated scanning with the CLSM without considerable bleaching effects. Statoliths after 3 incubations with 
A
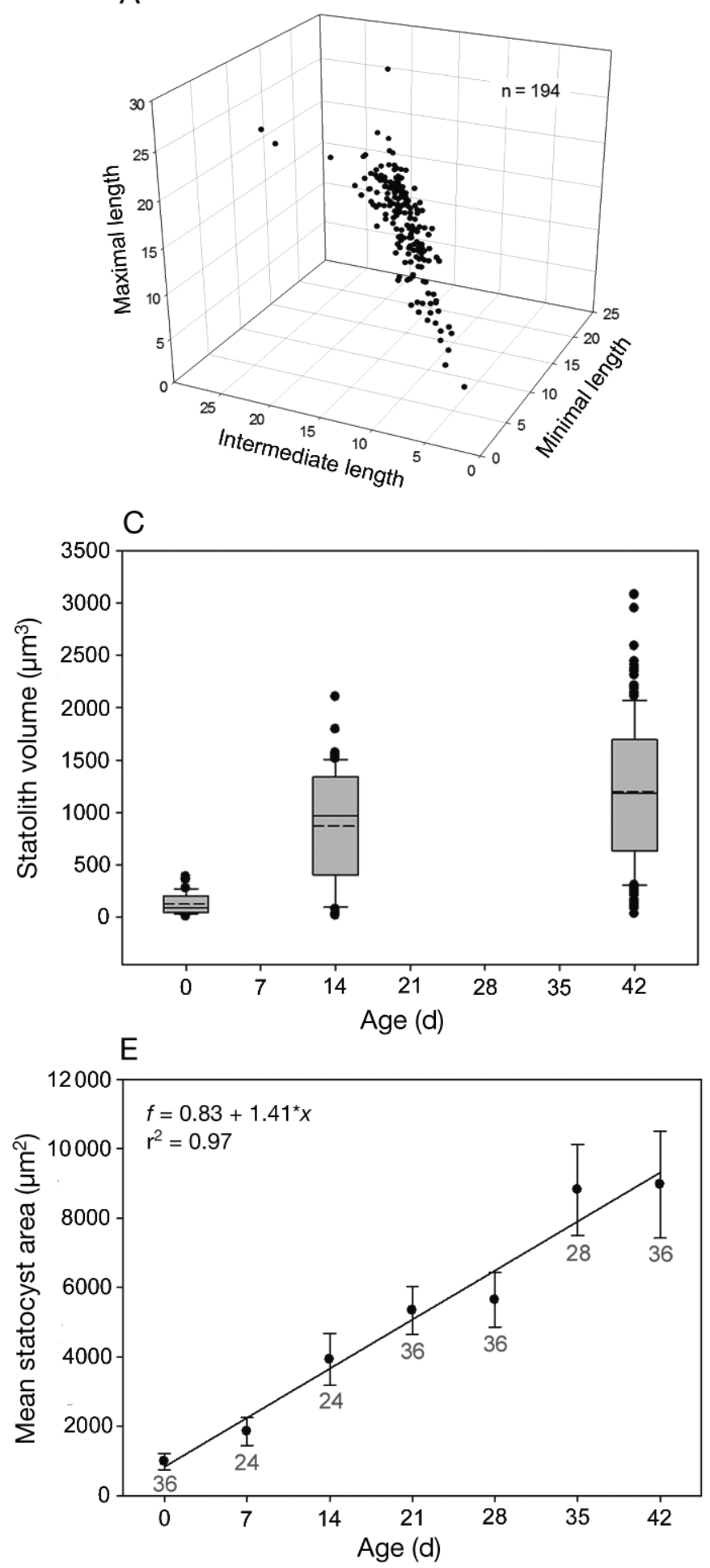
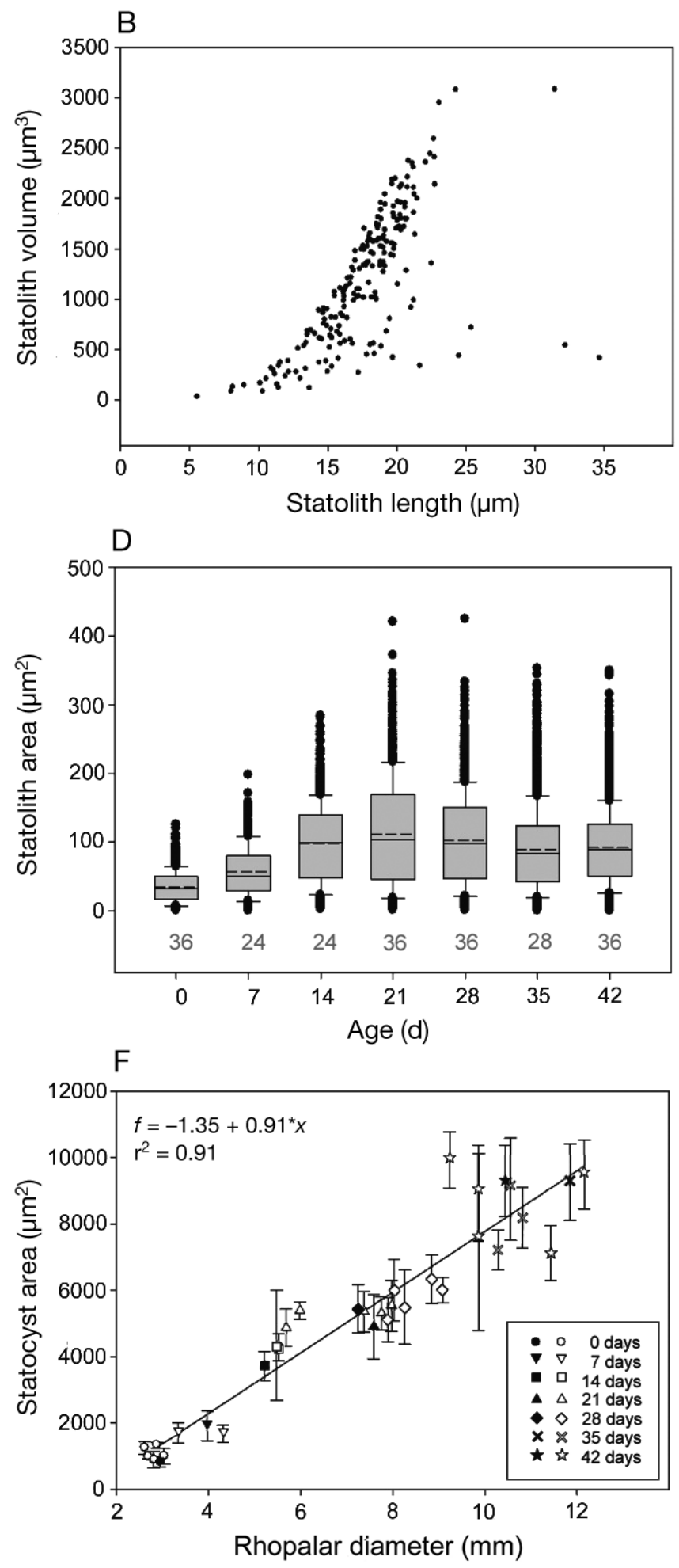

Fig. 7. Morphometric measurements of Sanderia malayensis statoliths and statocysts. (A-C) Automated measurements on tomographic statocyst reconstructions after label analysis of statoliths. (A) Length measurements on 3 axes on statoliths of $42 \mathrm{~d}$ old medusae. (B) Length vs. volume measurements on statoliths of $42 \mathrm{~d}$ old medusae. (C) Statolith volumes at 3 ages (1 statocyst each). (D-F) Light microscopic measurements on statoliths from ephyrae at different ages. (D) Statolith cross-sectional areas and means $( \pm \mathrm{SD})$ of $(\mathrm{E})$ statocyst cross-sectional areas and (F) individual statocyst cross-sectional areas in specimens of different sizes. In (C) and (D) dashed lines: mean values; lines: medians; vertical boxes: 25th and 75th percentiles; whiskers: 10th and 90th percentiles; dots: outliers. Grey numbers in (D) and (E): numbers of statocysts 
calcein (Treatments 3 and 4) showed 1 to 2 fluorescent hexagonal rings under excitation by cLSM, but 3 fluorescent rings were not detected in any of the statoliths. Statoliths after 2 incubations (Treatments 1 and 2) showed only 1 fluorescent hexagonal ring.

The statolith increments (distances between the inner and the outer hexagonal lines after 3 incubations) ranged from 1.6 to $4.9 \mu \mathrm{m}$ (mean $3.1 \pm 1.0 \mu \mathrm{m}$, $\mathrm{n}=60)$ in statoliths from Treatment $3\left(100 \mu \mathrm{mol} \mathrm{l}^{-1}\right)$ and from 1.4 to $3.8 \mu \mathrm{m}$ (mean $2.6 \pm 0.6 \mu \mathrm{m}, \mathrm{n}=156$ ) in statoliths from Treatment $4\left(200 \mu \mathrm{mol} \mathrm{l}^{-1}\right.$; Table S4 in the Supplement). Based on the assumption that the distance between the 2 rings reflected a growth phase of $2 \mathrm{wk}$, daily increments of 0.1 to $0.3 \mu \mathrm{m}$ (mean $0.2 \pm 0.1 \mu \mathrm{m}$ ) and of 0.1 to $0.3 \mu \mathrm{m}$ (mean $0.2 \pm$ $0.0 \mu \mathrm{m}$ ) on 1 statolith side face were calculated for Treatments 3 and 4 , respectively.

\section{Statolith chemistry}

EDX confirmed that all 6 analyzed statoliths from specimens of different ages were composed of calcium sulfate $\left(\mathrm{CaSO}_{4}\right)$. Oxygen, sulfur, and calcium showed characteristic peaks at energies of about 0.4, 2.3, and $3.7 \mathrm{eV}$, respectively (Fig. 8). Traces of the elements sodium and potassium were found in concentrations of $<1 \mathrm{~mol} \%$. The high concentration of carbon was caused by the sample preparation (graphite coating).

\section{Statocyst shape and growth}

The tomographic reconstructions confirmed that the smallest statoliths were detected in the proximal region of the statocyst (Fig. 6A-C). This was observed at all ages (Fig. 9), indicating that tiny young statoliths developed in this area, whereas the oldest statoliths were located at the opposite end of the statocysts. LM measurements revealed more slender statocysts in the $0 \mathrm{~d}$ old specimens (mean length: width ratio $2.5 \pm 0.5, \mathrm{n}=36$ ) compared to the thicker statocysts in the other ages $(7-42 \mathrm{~d}$, length:width ratio between 0.7 and 1.8 , mean $1.2 \pm 0.3, \mathrm{n}=184$; Fig. $9 \mathrm{~B}, \mathrm{E}, \mathrm{H})$. The length:width ratio of statocysts differed significantly among the 7 ages $(\mathrm{p} \leq 0.001$, Kruskal-Wallis ANOVA, $H=127.483$, df $6, \mathrm{n}=220$ ). The visualization of statocysts on different ages by tomographic reconstructions (Fig. 9C,F,I) confirmed differences in the spatial statolith arrangements, revealing statocyst shape modifications during early medusa development. The statolith arrangement of

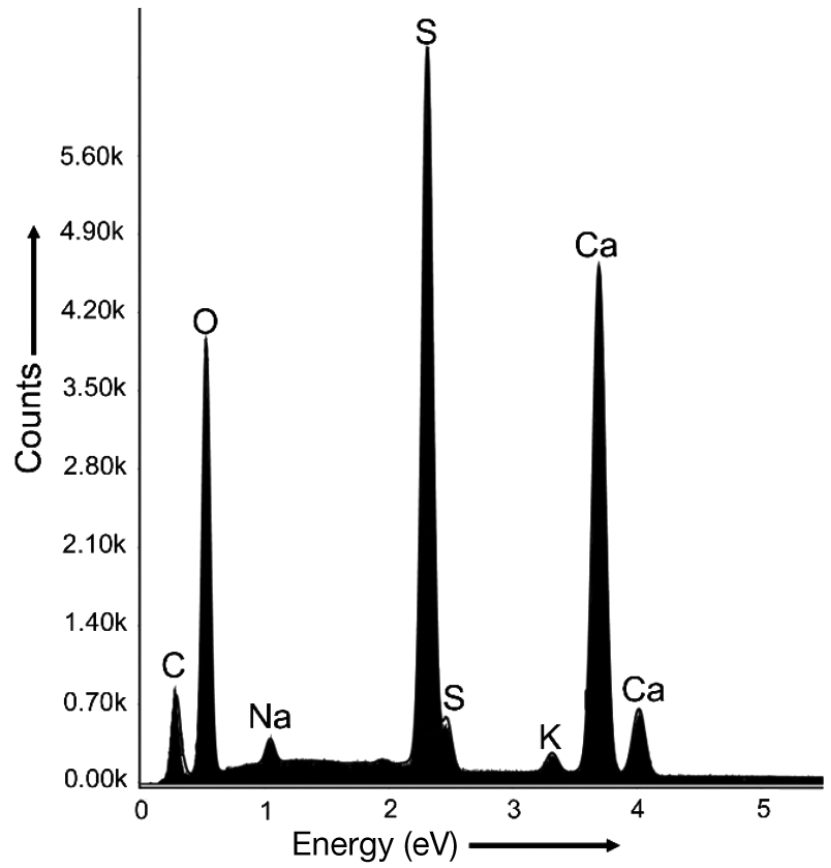

Fig. 8. Energy-dispersive X-ray spectra of Sanderia malayensis statoliths showing peaks for oxygen, sulfur, and calcium as characteristic for calcium sulfate

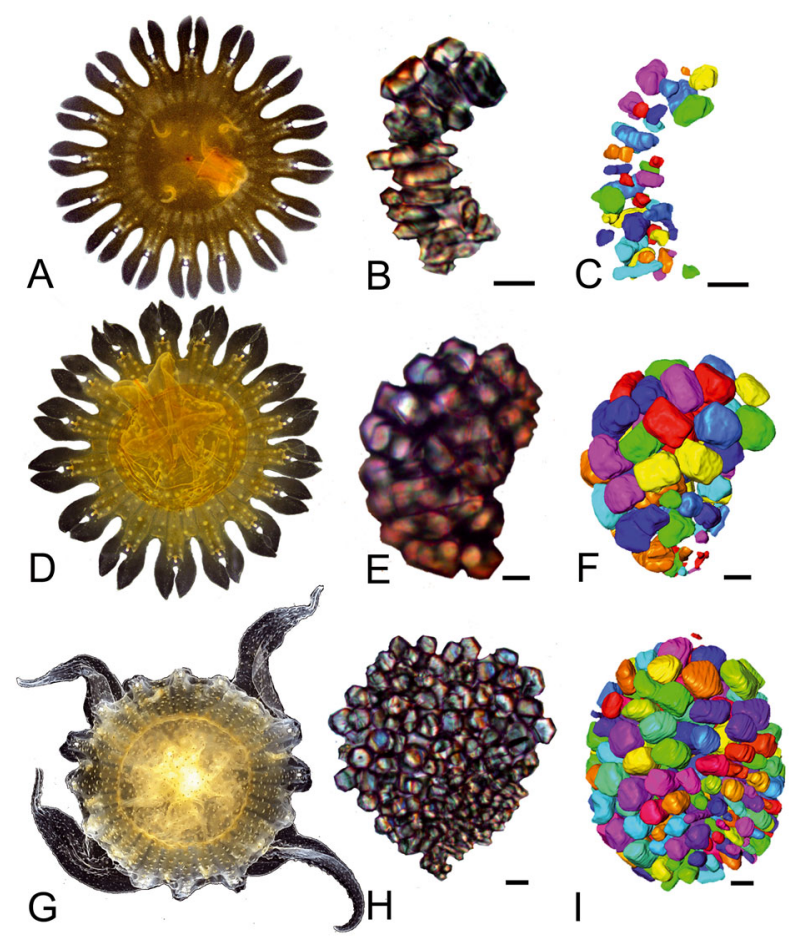

Fig. 9. $(\mathrm{A}, \mathrm{D}, \mathrm{G})$ Bell shapes of Sanderia malayensis ephyrae and medusae of different ages; $(B, E, H)$ related shapes of statocysts demonstrated by light microscopic photographs; and $(\mathrm{C}, \mathrm{F}, \mathrm{I})$ tomographic reconstructions after label analysis. (A-C) 0 d old specimen with crescent-shaped statocyst. (D-F) $14 \mathrm{~d}$ old specimen with kidney-shaped statocyst. (G-I) $42 \mathrm{~d}$ old specimen with round-oval statocyst. Scale bars $=10 \mu \mathrm{m}$ 
the newly released specimen was crescent-shaped (Fig. 9C) with length, width, and depth of 60.0, 33.8, and $25.2 \mu \mathrm{m}$, respectively, whereas the statolith arrangement of the $42 \mathrm{~d}$ old specimen was broader and round to oval (100.3, 108.9, and 93.2 $\mu \mathrm{m}$; Fig. 9I). Virtual slices through this large statocyst revealed that the statocyst was actually helmet-shaped with a cavity in the basal area (Fig. 6B). The statocyst of a $14 \mathrm{~d}$ old specimen was kidney-shaped $(74.9,63.8$, and $57.3 \mu \mathrm{m})$, suggesting a transition between the crescent- and helmet-shapes (Fig. 9F). The statocyst cross-sectional area (length $\times$ width) calculated from LM measurements was positively correlated to the $D_{\mathrm{t}}$ (Spearman correlation, $\mathrm{r}^{2}=0.933, \mathrm{p} \leq 0.001, \mathrm{n}=220$ ), to the $D_{\mathrm{r}}$ (Spearman correlation, $\mathrm{r}^{2}=0.930, \mathrm{p} \leq 0.001$, $\mathrm{n}=220$, Fig. 7F), and to the age of the specimens (Spearman correlation, $\mathrm{r}^{2}=0.933, \mathrm{p} \leq 0.001, \mathrm{n}=220$, Fig. 7E).

\section{DISCUSSION}

\section{Ephyra growth}

Previous studies on Sanderia malayensis focused on various asexual reproduction types (Uchida \& Sugiura 1978, Adler \& Jarms 2009), ephyra morphology (Uchida \& Sugiura 1975, Straehler-Pohl \& Jarms 2010), and the development of the gastric system in the early medusa (Straehler-Pohl et al. 2011). We present the first documentation of ephyra growth, including the morphological features appearing during transformation from ephyra into medusa. These results demonstrate that the size of the specimens and the temporal development of certain features like nematocyst clusters, tentacles, and pigmentation are not strictly related to the age of the specimens, as was documented similarly for other scyphozoan species (Russell 1970). We conclude that morphological features are unsuitable for age estimations because of the high plasticity of their development even under known stable conditions.

Our documented number of 9-21 rhopalia in the marginal lappet clefts in newly released ephyrae demonstrates the high variation of this feature that slightly differed from earlier descriptions (12-24) of $S$. malayensis ephyrae reared at the same temperature (Uchida \& Sugiura 1978). High variation in marginal lappets and related rhopalia numbers are common in scyphozoans from laboratory cultures (e.g. Straehler-Pohl \& Jarms 2010) as well as from the field (reviewed by Russell 1970). The strong correlation of bell diameter and age in $S$. malayensis resembles previous results of small, laboratory-reared Cassiopea sp. (Hopf \& Kingsford 2013). However, the bell diameter may grow continuously with age in laboratory-reared medusae under ideal constant conditions only (Lilley et al. 2014a). Medusae growth does not only include increases in the bell diameter, but also increasing bell thickness and growth, which can be defined by various parameters such as diameters, wet weight, dry weight, and carbon content (Pitt et al. 2013). We chose the equations for carbon weight and instantaneous growth rates previously used for Pelagia noctiluca (Lilley et al. 2014a) for calculations on $S$. malayensis because both species belong to the Pelagiidae. Our calculations are based on the assumption that both species have a similar body structure and thus should be regarded as rough estimates rather than reliable values. Calculated instantaneous growth rates of $S$. malayensis $\left(9-17 \% \mathrm{~d}^{-1}\right)$ were in the middle of the range of growth rates calculated for young stages of $P$. noctiluca $\left(0-30 \% \mathrm{~d}^{-1}\right)$ and of growth rates reported for other scyphozoan medusae (2-24\% d ${ }^{-1}$; reviewed by Lilley et al. 2014a). Higher growth rates calculated for younger stages of $S$. malayensis (Table S2) indicated decreasing growth with individual medusa size in accordance with results from $P$. noctiluca under both laboratory and field conditions (Lilley et al. 2014a).

In the field, medusa growth is affected by unstable food conditions, which can lead to a loss of body mass (degrowth) due to starvation and later regrowth under more favorable conditions (Fu et al. 2014, Lilley et al. 2014b, Goldstein \& Riisgård 2016). Other fluctuating environmental factors may also affect medusa growth, e.g. higher water temperatures that can lead to larger bell diameters in the laboratory (Hansson 1997, Widmer 2005). It has also been suggested that the energy allocated to sexual reproduction of medusae in the field can cause degrowth (Hansson 1997, Goldstein \& Riisgård 2016). If and how medusa statoliths are affected by degrowth and regrowth phases has not been investigated to date, but because of the lower structural plasticity of the calcified structures compared to soft tissues, others have suggested that they may be more reliable measures of age than the medusa size (Gordon et al. 2004, Hopf \& Kingsford 2013).

\section{Statolith number}

The number of statoliths per statocyst was successfully determined with LM methods. The use of a slide scanner enhanced the efficiency of the LM investiga- 
tions, but system adjustments by a specialist are highly recommended to avoid measurement errors. Automated counting was not possible because statoliths could not be differentiated from tissue remnants and air inclusions by the system, and adjacent statoliths were not identified as separate objects. MicroCT provided an alternative method that allowed automated determination of statolith numbers; however, the required label analysis of tomographic data is time-consuming (Holst et al. 2016). Statocysts of large scyphozoan medusae can contain several thousand statoliths (Sötje et al. 2011), and neither of the 2 methods tested allows a rapid automated counting of such large statolith numbers. Improved resolution and optical recognition in future imaging systems could reduce this problem.

Our results demonstrate high overlaps of statoliths per statocyst between the investigated size groups. Similar overlaps were also documented for other species (Table 2). Nevertheless, strong correlations of statolith numbers with medusa age and size were shown for normal specimens of $S$. malayensis and confirmed previous investigations on the scyphozoan species Rhizostoma octopus (Holst et al. 2007), Periphylla periphylla (Sötje et al. 2011), and Cassiopea sp. (Hopf \& Kingsford 2013). It is still unclear if the statolith number of scyphozoan jellyfish can be correlated to age or if the number is strictly dependent on the bell size. However, in both cases, statolith analyses can provide a promising tool for investigations on jellyfish population structures. Age determination of scyphozoan jellyfish would allow more precise backtracking models for jellyfish pathways in order to locate likely polyp habitats (Dulière et al. 2014, Gambill 2016). Little is known about the settlement areas of scyphozoan polyps, and their location is unknown for many species (van Walraven et al. 2016, Widmer et al. 2016). For this reason, only few in situ studies on scyphozoan polyps provide information on their seasonal abundances (e.g. Ishii \& Katsukoshi 2010) and the effects of environmental factors on the production of young jellyfish (strobilation) (e.g. Purcell

Table 2. Statoliths counted in the statocysts of young scyphozoans and species-specific predominant statolith shapes. Specimens were grouped by $2.5 \mathrm{~mm}$ groups up to $15 \mathrm{~mm}$ diameter or by $7 \mathrm{~d}$ age groups up to $42 \mathrm{~d}$. n: number of investigated specimens; nd: no data. Diameter refers to the total bell diameter, except in Periphylla periphylla, for which the coronal diameter was measured

\begin{tabular}{|c|c|c|c|c|c|}
\hline Species & $\begin{array}{l}\text { Diameter } \\
(\mathrm{mm})\end{array}$ & Age (d) & $\begin{array}{l}\text { Statoliths per } \\
\text { statocyst (n) }\end{array}$ & $\begin{array}{l}\text { Predominant } \\
\text { statolith shape }\end{array}$ & Reference \\
\hline Sanderia malayensis & $\begin{array}{c}2.6-5.0 \\
5.1-7.5 \\
7.6-10.0 \\
10.1-12.5 \\
12.6-15.0\end{array}$ & $\begin{array}{c}0-7 \\
7-14 \\
21-28 \\
35-42 \\
42\end{array}$ & $\begin{array}{c}15-55(7) \\
21-99(6) \\
54-157(8) \\
96-288(9) \\
85-260(4)\end{array}$ & Rod & Present study \\
\hline Rhizostoma octopus & $\begin{array}{c}0.1-2.5 \\
2.6-5.0 \\
5.1-7.5 \\
7.6-10.0 \\
10.1-12.5 \\
12.6-15.0\end{array}$ & nd & $\begin{array}{c}17-98(3) \\
32-68(2) \\
85-215(4) \\
97-264(3) \\
443-465(1) \\
329-448(1)\end{array}$ & Isodiametric & Holst et al. (2007) \\
\hline Periphylla periphylla & $\begin{array}{c}0.1-2.5 \\
2.6-5.0 \\
5.1-7.5 \\
7.6-10.0 \\
10.1-12.5 \\
12.6-15.0\end{array}$ & nd & $\begin{array}{c}12-39(3) \\
35-40(3) \\
\text { nd } \\
65-162(4) \\
127(1) \\
158-240(4)\end{array}$ & Rod & Sötje et al. (2011) \\
\hline Cassiopea andromeda & nd & $\begin{array}{c}0-7 \\
8-14 \\
15-21 \\
22-28 \\
29-35 \\
36-42\end{array}$ & $\begin{array}{c}18-120^{\mathrm{a}}(18) \\
60-140^{\mathrm{a}}(8) \\
120-220^{\mathrm{a}}(9) \\
135-265^{\mathrm{a}}(5) \\
100-285^{\mathrm{a}}(7) \\
200-315^{\mathrm{a}}(6)\end{array}$ & Disc & Hopf \& Kingsford (2013) \\
\hline Aurelia aurita & $\begin{array}{l}2.6-5.0 \\
5.1-7.5\end{array}$ & $\begin{array}{l}0-3 \\
\text { nd }\end{array}$ & $\begin{array}{c}17-19(3) \\
70\end{array}$ & Rod & Sötje et al. (2017) \\
\hline
\end{tabular}


et al. 2009). The strobilation process is linked to the development of jellyfish blooms (Boero et al. 2008, Holst 2012), and thus the realization of more in situ studies on polyps could help to understand the causes of blooming events.

The bell diameter composition and the related biomass are important parameters for conclusions on population dynamics and their functional effects of jellyfish (Makabe et al. 2012). Bell sizes also allow conclusions on the predatory impact and the fecundity of medusae (Goldstein \& Riisgård 2016). However, the determinations of bell diameters on living medusae from net hauls on board are challenging since each specimen has to be spread flat on a plate before measurement (Makabe et al. 2012). Moreover, the specimens can be damaged by nets (Båmstedt et al. 2003), leading to difficulties in correct measurements. Measurements on complete formalin-preserved medusae are possible in the laboratory (e.g. Morandini et al. 2017), but the fixation of complete medusae requires adequate storage space and large amounts of poisonous fixative which causes severe shrinkage (Holst \& Laakmann 2014, Laakmann \& Holst 2014), impeding the later determination of the original bell diameters. Statolith analyses in the laboratory could replace measurements on board or on preserved material if future studies confirm clear correlations of statolith numbers and bell sizes. The preservation of small bell rim pieces during collection would be sufficient for later statolith analyses, but high-proof ethanol is required for a sufficient preservation of statoliths (Holst et al. 2016). The ethanol-preserved bell rim pieces could also be used in parallel for molecular genetic analyses allowing conclusions on population genetic structure (Lee et al. 2013, Dawson et al. 2015, Glynn et al. 2016).

Scyphomedusan degrowth can occur synchronously with sexual reproduction (Goldstein \& Riisgård 2016) and was also reported in overwintering populations (Makabe et al. 2012). Positive correlations among statolith numbers and bell diameters are probably limited to growth phases. In conclusion, analyses of statolith numbers of degrown and overwintered populations could allow conclusions on the earlier maximum bell size on an individual level, which may provide more precise data on the overwintering population structure than analyses of bell diameter compositions (Makabe et al. 2012).

$S$. malayensis statocysts contained fewer statoliths than $R$. octopus medusae of similar sizes (Holst et al. 2007 ) or Cassiopea sp. medusae of similar ages (Hopf \& Kingsford 2013) (Table 2). We found fewer statoliths in specimens with malformations than in nor- mally developed ones. Because malformations and variable numbers of marginal lappets are frequent in young scyphozoans in the laboratory (e.g. Holst et al. 2007, Straehler-Pohl \& Jarms 2010, Algueró-Muñiz et al. 2016, this study), possible effects on statolith numbers should be considered in future studies.

\section{Statolith shapes}

Statolith measurements by light microscopic methods provided reliable data on $S$. malayensis statolith morphometry. Our results revealed differences in the percentages of statolith shape types (Fig. 5B), defined by the statolith aspect ratios, among the investigated ages. It was suggested that the growth of individual statoliths may be affected by the surrounding statoliths and that statolith shapes may depend on the growth and development of the whole statocyst (Sötje et al. 2017). Needle-shaped statoliths were most abundant in newly released $S$. malayensis ephyrae and in the proximal end of the statocyst leading to the assumption that the needle shape could be the initial shape of newly developed statoliths which later transform to other shapes during statolith growth. However, needle-shaped statoliths were not found in the statocysts of newly released Aurelia aurita ephyrae (Sötje et al. 2017), indicating that the needle shape is not necessarily the initial statolith shape and that statolith development could be species-specific. We revealed the rod shape as the typical statolith type in $S$. malayensis, which was also typical for $A$. aurita and $P$. periphylla, whereas the typical shape of $R$. octopus statoliths was approximately equilateral and that of Cassiopea sp. was disc-shaped (Table 2). Even though a rod shape appears to be the predominant shape in the taxa Coronatae (P. periphylla), Cyaneidae (Cyanea capillata, C. lamarckii), Cepheidae (Cotylorhiza tuberculata), Ulmaridae (A. aurita), and Pelagiidae (S. malayensis), different species show differences in statolith shapes and in shape compositions (Tiemann et al. 2002, Becker et al. 2005, Boßelmann et al. 2007). Rodand needle-shaped statoliths, but no isodiametric or disc-shaped crystals, were detected in A. aurita (Sötje et al. 2017), whereas isodiametric, rod-, needle-, and disc-shaped crystals were present in S. malayensis (this study).

SEM micrographs provided a good additional tool for depiction of statolith shapes of some statoliths, but could not reflect the broad variability of statolith shapes and sizes in the statocyst. The dissolution of the pointed tips at the statolith head-faces in the SEM 
micrographs probably occurred after death of the specimens (Sötje et al. 2017). The extent of the dissolution process may depend on the amount of water in the tissue surrounding the statocyst during fixation, and thus, it is important to minimize the amount of surrounding tissue and to keep the amount and proof of ethanol high during the fixation of statoliths.

A limitation of LM and SEM was that the statoliths were visualized only in 2 dimensions. Therefore, only side-face-oriented statoliths were useful for the LM evaluation of aspect ratios, whereas measurements on head-face-oriented statoliths reflected variations in the statolith cross profile only (Fig. 5C). In contrast, micro-CT analyses provided statolith measurements of all statoliths in 3 dimensions. However, the method was not suitable to display the shapes and sizes of statoliths as accurately as was possible by LM, probably because of the limited image resolution. Thus, the method was not suitable to display the appearance of different shape types in different stages. Nevertheless, the scatter plots of automated measurements are potentially useful for intra- and interspecific comparisons of scyphozoan statoliths (Holst et al. 2016). The distribution pattern shown in our plots for $S$. malayensis (Fig. 7A,B) resemble the pattern in the plots of micro-CT data for statoliths of $C$. lamarckii (compare Fig. 8B,C in Holst et al. 2016). These similarities may reflect a close phylogenetic relationship of the 2 species, which both belong to the scyphozoan taxon Semeostomeae. The potential of interspecific statolith shape comparisons was shown for the single large statoliths in the statocysts of Cubozoa (Mooney \& Kingsford 2016a, 2017). Micro-CT provides a suitable tool for interspecific comparisons of statolith shapes. Improvement of the spatial resolution and efficiency in future micro-CT systems will lead to enhanced 3-dimensional visualization of statoliths and will allow comparisons among many species from various taxonomic levels useful for phylogenetic comparisons.

\section{Statolith size and growth}

As in previous studies (Holst et al. 2007, Sötje et al. 2011), our results revealed a positive correlation of statolith size and medusa age. However, closer examination of the data indicates significant statolith size increase in younger medusa stages only. For example, maximum statolith widths of the 5 largest statoliths measured increased in $P$. periphylla from 15 to around $45 \mu \mathrm{m}$ in medusae of $2-23 \mathrm{~mm}$ in diameter, but the mean widths did not increase considerably in larger medusae with diameters up to
$185 \mathrm{~mm}$ (with 1 exception of $53 \mu \mathrm{m}$ mean width; see Fig. 5C in Sötje et al. 2011). Increments in statoliths were used to back-date the age of the cubomedusa Chironex fleckeri (Gordon \& Seymour 2012). Our data now indicate that in scyphozoans, the statolith size does not allow conclusions about medusa diameter or age because statoliths stop, or at least considerably slow growth, when a certain size is reached. Instead, the determination of statolith numbers is a promising parameter for the age determination or bell size correlations of scyphozoan medusae (see discussion on statolith number above). The largest statolith volumes measured on micro-CT data of Cyanea lamarckii were around $10000 \mu^{3}$ (Holst et al. 2016), more than 3 times larger compared to the statolith volumes in S. malayensis (around $3000 \mu^{3}$; Fig. 7B), suggesting that maximum statolith size could be species-specific. Studies on the statoliths of A. labiata epyhrae (Winans \& Purcell 2010) and young cubomedusae (Klein et al. 2014) indicate that different $\mathrm{pH}$ conditions could affect the growth of statoliths, but this may be caused by secondary effects of low $\mathrm{pH}$ on feeding and thus energy available to build the bassanite crystals (Tills et al. 2016). High intraspecific variation in statolith sizes were also documented for specimens cultured under the same laboratory conditions (Winans \& Purcell 2010, this study). Further analyses are required to detect if differences in statolith size are caused by environmental effects or if they represent inter- or even intraspecific variation.

Differences in the statolith composition in different ages of $S$. malayensis were represented by different percentages of shape types (Fig. 5B). Statoliths with isogonal or irregular hexagonal statolith cross profiles were not present in the $0 \mathrm{~d}$ old specimens, but appeared in older ones (Fig. 5C). These results indicate a change in crystal shapes by statolith growth, as previously suggested for A. aurita statoliths (Sötje et al. 2017). As shown by Sötje et al. (2017), our study demonstrated that statolith growth can be visualized by using calcein as a fluorescent marker. This method allowed calculations of the daily statolith size increase of $0.2 \mu \mathrm{m}$ for $S$. malayensis. The lower mean daily increment of $0.1 \mu \mathrm{m}$ calculated for $A$. aurita statoliths was probably caused by the lower culture temperature of $12^{\circ} \mathrm{C}$ (Sötje et al. 2017). The hexagonal ring structures detected in $S$. malayensis statoliths by LM in 1000 -fold magnification (Fig. 2H,I) showed rings of 1-2 $\mu \mathrm{m}$, which was about a factor of 10 wider than the daily statolith increment calculated from the calcein experiments. In conclusion, it is unlikely that these ring 
structures represented daily statolith growth, as assumed for the ring structures in cubozoan statoliths (Kawamura et al. 2003, Gordon et al. 2004, Gordon \& Seymour 2012).

In our methods, the time interval between the first and the second calcein incubations (4 wk) differed from the interval between the second and the third incubations ( $2 \mathrm{wk})$, which led to difficulties in interpretation of our results. The application of 3 calcein treatments could cause various scenarios of resulting fluorescent markings in the statoliths depending on the degree of statolith development (Fig. S1). We detected only 1 fluorescent ring after 2 incubations and only 2 rings after 3 incubations, probably because the statoliths had reached their final size within 3 wk as indicated by our LM measurements (Fig. 7D). We concluded that the distances measured between the 2 fluorescent rings (after 3 treatments) represented a growth phase of 2 wk because few statoliths were present in the newly detached ephyrae used for the first incubation, and those few statoliths probably were not detected among the many statoliths that had developed by the third incubation in $42 \mathrm{~d}$ old specimens. For the same reason, only statoliths with 1 fluorescent hexagonal ring were found in specimens after 2 calcein incubations (Fig. S1 in the Supplement). For successful calcein treatment, the calcein molecules are surrounded by bassanite while the statolith grows; thereby the fluorescent calcium is incorporated into the crystal (Sötje et al. 2017). Conversely, calcein has no effect if the statoliths do not grow by bassanite increments after the incubation. The statoliths that appeared without fluorescent rings in our samples had probably developed after the first incubation and stopped growing before the second incubation (scenario VII in Fig. S1). To avoid such interpretation problems, we recommend keeping the same time intervals of $2 \mathrm{wk}$ or less between calcein incubations. Because only head-face-oriented crystals can be used for the analyses of calceinlabeled statoliths (Sötje et al. 2017), it may be advantageous to use specimens older than 1 wk that may contain higher percentages of head-faceoriented (disc-shaped) statoliths in their statocysts than newly released ephyrae (Fig. 5A). Treatments with a calcein concentration of $100 \mu \mathrm{mol} \mathrm{l}^{-1}$ for $3 \mathrm{~d}$ are recommended for future studies, because they led to sufficient fluorescent markings in the bassanite statoliths (Sötje et al. 2017, this study). Lower calcein concentration $\left(50 \mu \mathrm{mol} \mathrm{l^{-1 }}\right)$ was insufficient to label A. aurita statoliths (Sötje et al. 2017), and higher concentration $\left(200 \mu \mathrm{mol} \mathrm{l}^{-1}\right)$ did not improve the results over $100 \mu \mathrm{mol} \mathrm{l}^{-1}$ in our study on $S$. malayensis statoliths.

\section{Statolith chemistry}

The EDX analyses of $S$. malayensis statoliths showed mainly calcium, sulfur, and oxygen, indicating the presence of calcium sulfate (Becker et al. 2005). It is likely that the statoliths were composed of bassanite, a calcium sulfate subhydrate, as previously shown for other scyphozoan and cubozoan statoliths by single X-ray diffraction (Becker et al. 2005, Tiemann et al. 2006, Sötje et al. 2011). EDX, however, is not suitable to distinguish calcium sulfate dehydrate (gypsum) from the subhydrate, which led to misinterpretations of the statolith material in earlier studies on some scyphozoan and cubozoan species (reviewed by Becker et al. 2005). Unequivocal identification of the calcium sulfated subhydrate is possible only by single-crystal X-ray analysis. The drawback of the method is the requirement of special diffractometer technologies, whereas EDX can be conducted with an SEM system, which is available to a broad group of scientists.

\section{Statocyst size and shape}

Previous positive correlations between scyphozoan statocyst sizes and medusa diameters (Holst et al. 2007, Sötje et al. 2011) were confirmed for S. malayensis (Fig. 7F). The statocyst cross-sectional area was also correlated with the age of the specimens (Fig. 7E), suggesting that this parameter could be useful for an age determination. However, because of the complex structure of the statocyst, the simple detection of the statocyst length and width from 2dimensional photographs is insufficient to reflect the actual statocyst volumes. Measurements on tomographic data could provide more exact determinations of statocyst volumes and shapes, but current micro-CT techniques are unsuitable for large-scale investigations. Instead, tomographic data are useful for interspecific comparisons on the arrangement of statoliths reflecting the statocyst shapes (Holst et al. 2016). Our results on statocyst shape modifications during the early medusa development of $S$. malayensis (Fig. 9) indicated that statocyst shapes can differ considerably from young specimens to adults, which should be considered in future investigations on interspecific differences of statocyst shapes and volumes. 


\section{Environmental effects on medusa and statolith development}

Our results on ephyra development demonstrate that differences in the appearance of certain morphological features are not necessarily linked to different environmental conditions and thus are usually not useful indicators for environmental effects. Laboratory experiments on $A$. aurita ephyrae suggest that they are not likely to suffer from environmental changes related to climate change (ocean acidification, warming, and deoxygenation) in the near future (Algueró-Muñiz et al. 2016). However, the few available data on environmental and nutritional effects on statoliths indicate that these parameters can affect statolith numbers or sizes. Statolith numbers of the scyphozoan Cassiopea sp. were affected by temperature, but not by salinity or food in experimental studies (Hopf \& Kingsford 2013), and pH affected statolith sizes but not numbers in A. labiata (Winans \& Purcell 2010). Although reduced $\mathrm{pH}$ has no direct dissolution effects on calcium sulfate subhydrate composed statoliths, A. aurita ephyrae exposed to reduced seawater $\mathrm{pH}$ showed a decrease in pulsation rate probably because of secondary effects of low $\mathrm{pH}$ on feeding and thus energy available for the growth of statoliths (Tills et al. 2016). More experimental research including the combination of laboratory and field data, might lead to more reliable conclusions on environmental effects on statolith and statocyst development. Studies on cubozoan medusae indicated a high potential for the reconstruction of medusa movements by statolith elemental chemistry in areas with known salinity and temperature gradients (Mooney \& Kingsford 2016b) which may also be true for scyphozoans. In turn, statolith analyses could be used to conclude on environmental conditions.

\section{CONCLUSIONS}

Statoliths represent the only hard structures in the gelatinous bodies of scyphozoan jellyfish and thus could be a very useful tool for age determination and phylogenetic analyses. Our methodical approach provides a comparison of various investigation techniques for scyphozoan statoliths, revealing the possibilities and advantages of certain techniques to support a successful experimental design of future studies on scyphozoan statoliths. Reliable determination of statolith numbers and sizes is possible by LM and micro-CT analyses. Both methods are timeconsuming with the currently available techniques, but the optimization of optical systems may accelerate the processing time in future studies. Calcein labeling is a suitable method to follow statolith growth and to calculate daily increments, which may differ with culture temperature. Statolith numbers could be useful for age estimation of scyphozoan jellyfish because the numbers increase continuously with medusa size and age in the laboratory, unlike statolith size, which seems to reach a maximum and cannot be linked to a certain developmental stage or age. Statolith and statocyst morphometry can be documented by LM and SEM analyses, but those data are based on 2-dimensional measurements that do not reflect the actual volumes of the structures. Micro-CT allows 3-dimensional depictions and measurements of statoliths and statocysts, but the limited resolution of the system we used did not allow for sufficient representation of statolith shapes.

In conclusion, a combination of microscopic and micro-tomographic techniques is recommended for investigations on interspecific comparisons on statolith shapes and statocyst shapes, which may provide useful tools for phylogenetic studies on scyphozoans. Additional studies comparing specimens reared in the laboratory and from the field, experimental studies on the effects of environmental conditions on statoliths, as well as studies on a broad range of taxa in various developmental stages are necessary to determine the scope of applications of statoliths in demographic and phylogenetic studies on scyphozoan jellyfish. Further work would contribute to refine methodological approaches and to reduce the time and cost expense of statolith analyses, which would help to establish statolith analyses as a standard method in jellyfish taxonomy and ecology.

Acknowledgements. We thank Frank Friedrich, Pascal Meyer, Janina Fiebig, Stephan Henne, Sabine Gaude, Renate Walter, and Svenja Warnke for their technical support in sample preparation and helpful advice on microscopy and software application, and Peter Michalik and Jakob Krieger for their help in micro-CT processing. We thank Sea Pen Scientific Writing for editing services and 2 anonymous reviewers for their comments improving the manuscript. This manuscript is based on the MSc thesis of A.H. conducted at the University of Oldenburg. We thank Pedro Martínez-Arbizu for co-supervising the thesis. This study was funded by the German Science Foundation (DFG SO 1238/2-1, DFG HO 4097/3-1).

\section{LITERATURE CITED}

Adler L, Jarms G (2009) New insights into reproductive traits of scyphozoans: special methods of propagation in Sanderia malayensis GOETTE, 1886 (Pelagiidae, Semaeostomeae) enable establishing a new classification of 
asexual reproduction in the class Scyphozoa. Mar Biol 156:1411-1420

Algueró-Muñiz M, Meunier CL, Holst S, Alvarez-Fernandez S, Boersma M (2016) Withstanding multiple stressors: ephyrae of the moon jellyfish (Aurelia aurita, Scyphozoa) in a high-temperature, high- $\mathrm{CO}_{2}$ and low-oxygen environment. Mar Biol 163:185

* Båmstedt U, Kaartvedt S, Youngbluth M (2003) An evaluation of acoustic and video methods to estimate the abundance and vertical distribution of jellyfish. J Plankton Res 25:1307-1318

Barroso CM, Nunes M, Richardson CA, Moreira MH (2005) The gastropod statolith: a tool for determining the age of Nassarius reticulatus. Mar Biol 146:1139-1144

*Becker A, Sötje I, Paulmann C, Beckmann F and others (2005) Calcium sulfate hemihydrate is the inorganic mineral in statoliths of Scyphozoan medusae (Cnidaria). Dalton Trans 1545-1550

* Boero F, Boullion J, Gravili C, Miglietta MP, Parsons T, Piraino S (2008) Gelatinous plankton: irregularities rule the world (sometimes). Mar Ecol Prog Ser 356:299-310

Boßelmann F, Epple M, Sötje I, Tiemann H (2007) Statoliths of calcium sulfate hemihydrate are used for gravity sensing in rhopaliophoran medusae (Cnidaria). In: Bäuerlein E (ed) Handbook of biomineralization: biological aspects and structure formation. Wiley-VCH Verlag, Weinheim, p 262-272

Dawson MN, Cieciel K, Decker MB, Hays GC, Lucas CH, Pitt KA (2015) Population-level perspectives on global change: genetic and demographic analyses indicate various scales, timing, and causes of scyphozoan jellyfish blooms. Biol Invasions 17:851-867

Dulière V, Kerckhof F, Lacroix G (2014) Where is my jelly? De Strandvlo 34:48-65

Fu Z, Shibata M, Makabe R, Ikeda H, Uye S (2014) Body size reduction under starvation, and the point of no return, in ephyrae of the moon jellyfish Aurelia aurita. Mar Ecol Prog Ser 510:255-263

Gambill M (2016) Ecophysiology and life cycle dynamics of North Sea gelatinous zooplankton. PhD dissertation, University of Hamburg

* Glynn F, Houghton JDR, Bastian T, Doyle TK, Fuentes V, Lilley MKS, Provan J (2016) High-resolution genetic analysis reveals extensive gene flow within the jellyfish Pelagia noctiluca (Scyphozoa) in the North Atlantic and Mediterranean Sea. Biol J Linn Soc 117:252-263

* Goldstein J, Riisgård HU (2016) Population dynamics and factors controlling somatic degrowth of the common jellyfish, Aurelia aurita, in a temperate semi-enclosed cove (Kertinge Nor, Denmark). Mar Biol 163:33

*Gordon M, Seymour J (2012) Growth, development and temporal variation in the onset of six Chironex fleckeri medusae seasons: a contribution to understanding jellyfish ecology. PLOS ONE 7:e31277

* Gordon M, Hatcher C, Seymour J (2004) Growth and age determination of the tropical Australian cubozoan Chiropsalmus sp. Hydrobiologia 530-531:339-345

Hansson LJ (1997) Effect of temperature on growth rate of Aurelia aurita (Cnidaria, Scyphozoa) from Gullmarsfjorden, Sweden. Mar Ecol Prog Ser 161:145-153

Holst S (2012) Effects of climate warming on strobilation and ephyra production of North Sea scyphozoan jellyfish. Hydrobiologia 690:127-140

Holst S, Laakmann S (2014) Morphological and molecular discrimination of two closely related jellyfish species,
Cyanea capillata and C. lamarckii (Cnidaria, Scyphozoa), from the northeast Atlantic. J Plankton Res 36:48-63

Holst S, Sötje I, Tiemann H, Jarms G (2007) Life cycle of the rhizostome jellyfish Rhizostoma octopus (L.) (Scyphozoa, Rhizostomeae), with studies on cnidocysts and statoliths. Mar Biol 151:1695-1710

* Holst S, Michalik P, Noske M, Krieger J, Sötje I (2016) Potential of X-ray micro-computed tomography for softbodied and gelatinous cnidarians with special emphasis on scyphozoan and cubozoan statoliths. J Plankton Res 38:1225-1242

*Hopf JK, Kingsford MJ (2013) The utility of statoliths and bell size to elucidate age and condition of a scyphomedusa (Cassiopea sp.). Mar Biol 160:951-960

Ishii H, Katsukoshi K (2010) Seasonal and vertical distribution of Aurelia aurita polyps on a pylon in the innermost part of Tokyo Bay. J Oceanogr 66:329-336

Kawamura M, Ueno S, Iwanaga S, Oshiro N, Kubota S (2003) The relationship between fine rings in the statolith and growth of the cubomedusa Chiropsalmus quadrigatus (Cnidaria: Cubozoa) from Okinawa Island, Japan. Plankton Biol Ecol 50:37-42

Klein SG, Pitt KA, Rathjen KA, Seymour JE (2014) Irukandji jellyfish polyps exhibit tolerance to interacting climate change stressors. Glob Change Biol 20:28-37

Laakmann S, Holst S (2014) Emphasizing the diversity of North Sea hydromedusae by combined morphological and molecular methods. J Plankton Res 36:64-76

K Lee PLM, Dawson M, Neill SP, Robins PE, Houghton JDR, Doyle TK, Hays GC (2013) Identification of genetically and oceanographically distinct blooms of jellyfish. J R Soc Interface 10:20120920

Killey MKS, Ferraris M, Elineau A, Berline L and others (2014a) Culture and growth of the jellyfish Pelagia noctiluca in the laboratory. Mar Ecol Prog Ser 510:265-273

Lilley MKS, Elineau A, Ferraris M, Thiery A, Stemmann L, Gorsky G, Lombard F (2014b) Individual shrinking to enhance population survival: quantifying the reproductive and metabolic expenditures of a starving jellyfish, Pelagia noctiluca. J Plankton Res 36:1585-1597

* Makabe R, Kurihara T, Uye SI (2012) Spatio-temporal distribution and seasonal population dynamics of the jellyfish Aurelia aurita s.l. studied with Dual-frequency IDentification SONar (DIDSON). J Plankton Res 34:936-950

* Mooney CJ, Kingsford MJ (2016a) Statolith morphometrics can discriminate among taxa of cubozoan jellyfishes. PLOS ONE 11:e0155719

*Mooney CJ, Kingsford MJ (2016b) The influence of salinity on box jellyfish (Chironex fleckeri, Cubozoa) statolith elemental chemistry. Mar Biol 163:103

Mooney CJ, Kingsford MJ (2017) Statolith morphometrics as a tool to distinguish among populations of three cubozoan species. Hydrobiologia 787:111-121

Morandini AC, Stampar SN, Maronna MM, Da Silveira FL (2017) All non-indigenous species were introduced recently? The case study of Cassiopea (Cnidaria: Scyphozoa) in Brazilian waters. J Mar Biol Assoc UK 97:321-328

Panfili J, Tomás J, Morales-Nin B (2009) Otolith microstructure in tropical fish. In: Green BS, Mapstone BD, Carlos G, Begg GA (eds) Tropical fish otoliths: information for assessment, management and ecology. Reviews: methods and technologies in fish biology and fisheries, Vol 11. Springer, New York, NY, p 212-248

Pitt KA, Duarte CM, Lucas CH, Sutherland KR and others (2013) Jellyfish body plans provide allometric advan- 
tages beyond low carbon content. PLOS ONE 8:e72683

Purcell JE, Hoover RA, Schwarck NT (2009) Interannual variation of strobilation by the scyphozoan Aurelia labiata in relation to polyp density, temperature, salinity, and light conditions in situ. Mar Ecol Prog Ser 375:139-149

Rodhouse PG, Hatfield EMC (1990) Age determination in squid using statolith growth increments. Fish Res 8: 323-334

Russell FS (1970) The medusae of the British Isles II. Pelagic Scyphozoa with a supplement to the first volume on hydromedusae, Vol 2. Cambridge University Press, Cambridge

Schiariti A, Melica V, Kogovšek T, Malej A (2015) Densitydependent effects control the reproductive strategy and population growth of Aurelia aurita s.l. scyphistomae. Mar Biol 162:1665-1672

Sötje I, Neues F, Ludwig W, Rack A, Gordon M, Boese R, Tiemann H (2011) Comparison of the statolith structures of Chironex fleckeri (Cnidaria, Cubozoa) and Periphylla periphylla (Cnidaria, Scyphozoa): a phylogenetic approach. Mar Biol 158:1149-1161

Sötje I, Dishon T, Hoffmann F, Holst S (2017) New methods of morphometric analyses on scyphozoan jellyfish statoliths including the first direct evidence for statolith growth using calcein as a fluorescent marker. Microsc Microanal 23:553-568

Straehler-Pohl I, Jarms G (2010) Identification key for young ephyrae: a first step for early detection of jellyfish blooms. Hydrobiologia 645:3-21

Straehler-Pohl I, Widmer CL, Morandini AC (2011) Characterizations of juvenile stages of some semaeostome Scyphozoa (Cnidaria), with recognition of a new family

Editorial responsibility: Fabien Lombard (Guest Editor), Villefranche-sur-Mer, France
(Phacellophoridae). Zootaxa 2741:1-37

Tiemann H, Sötje I, Jarms G, Paulmann C, Epple M, Hasse B (2002) Calcium sulfate hemihydrate in statoliths of deepsea medusae. J Chem Soc Dalton Trans 2002:1266-1268

Tiemann H, Sötje I, Becker A, Jarms G, Epple M (2006) Calcium sulfate hemihydrate (bassanite) statoliths in the cubozoan Carybdea sp. Zool Anz 245:13-17

* Tills O, Sun X, Rundle SD, Heimbach T and others (2016) Reduced $\mathrm{pH}$ affects pulsing behaviour and body size in ephyrae of the moon jellyfish, Aurelia aurita. J Exp Mar Biol Ecol 480:54-61

Uchida T, Sugiura Y (1975) On the ephyra and postephyra of a semaeostome medusa, Sanderia malayensis Goette. J Fac Sci Hokkaido Univ Ser VI Zool 19:879-881

Uchida T, Sugiura Y (1978) On the polyp of the scyphomedusa, Sanderia malayensis and its reproduction. J Fac Sci Hokkaido Univ Ser VI Zool 21:279-286

* van Walraven L, Driessen F, van Bleijswijk J, Bol A and others (2016) Where are the polyps? Molecular identification, distribution and population differentiation of Aurelia aurita jellyfish polyps in the southern North Sea area. Mar Biol 163:172

Widmer CL (2005) Effects of temperature on growth of north-east Pacific moon jellyfish ephyrae, Aurelia labiata (Cnidaria: Scyphozoa). J Mar Biol Assoc UK 85:569-573

*Widmer CL, Fox CJ, Brierley AS (2016) Effects of temperature and salinity on four species of northeastern Atlantic scyphistomae (Cnidaria: Scyphozoa). Mar Ecol Prog Ser 559:73-88

Winans AK, Purcell JE (2010) Effects of pH on asexual reproduction and statolith formation of the scyphozoan, Aurelia labiata. Hydrobiologia 645:39-52

Submitted: December 30, 2016; Accepted: August 3, 2016 Proofs received from author(s): September 18, 2017 